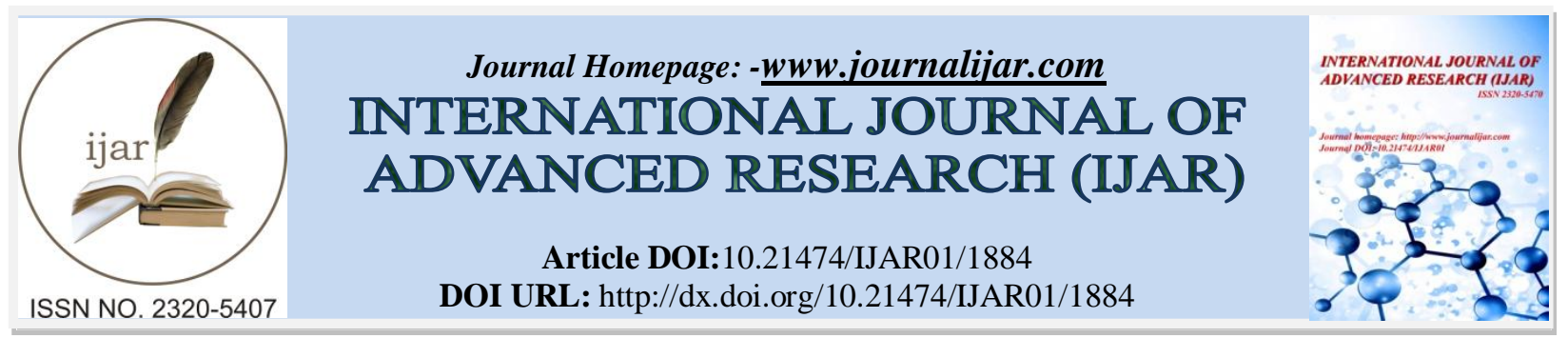

RESEARCH ARTICLE

\title{
2D AND 3D NUMERICAL MODELING OF THE HAJJAR MAGNETIC CENTRAL OREBODY.
}

Saad Soulaimani ${ }^{1}$, Fatima EL Hmidi ${ }^{1}$, Ahmed Manar ${ }^{2}$, Said Chakiri ${ }^{1}$ and Wafae Nouaim ${ }^{1}$.

1. Universite Ibn Tofail, Faculte des Sciences, Laboratoire Geosciences des Ressources Naturelles, B.P 133, 14000, Kenitra, Maroc.

2. Ministere de l'Energie, des Mines, de l'Eau et de l'Environnement, Rabat Instituts 6208 - Haut Agdal - Rabat, Maroc

\section{Manuscript Info}

Manuscript History

Received: 12 August 2016

Final Accepted: 22 September 2016

Published: October 2016

Key words:-

Numerical Modeling, Magnetic method, HAJJAR Mine, GM-SYS 3D, Forward model, 2D, 3D, Inversion, PotentQ.

\section{Abstract}

The choice of the Hajjar mine was not randomly selected. The Hajjar ore body and following its geophysics properties is regarded as a typical example to make several geophysics studies. The gravimetric and magnetic data allows validating several geophysics models by different methods.

However, our goal is modelling the ore body mining resource while being based on the magnetic processing and data analysis, by using Oasis montaj software, we will make possible an almost exact morphology and define different ore body parameters.

The 2D and 3D modelization to the mining resource. While being based on two approaches, the first is based on themagnetic processing, data analysisand 2D inversion by Different extensions (PotentQ and Oasis montaj inversion) to define different ore body parameters. The second is 3D Forward modelling by GM-SYS 3D. The last model will allow us to definethe distribution of the susceptibility as 3 components $(\mathrm{x}, \mathrm{y}, \mathrm{z})$ in the basement of the regionand $3 \mathrm{D}$ representation of ore body.

Copy Right, IJAR, 2016,. All rights reserved

\section{Introduction: -}

Since the thirties of the last century, the Guemassa region was the seat of several geophysical campaigns to the deposits searching after the discovery of the Kettara ore body (Jebilet region).

The DouarHajjar's massive sulphide is a target for geophysical exploration upon the location of aeromagnetic anomalies carried out in 1968.

Indeed, several studies have been conducted on the region by the B.R.P.M (Bureau and Mining Research Participation), the B.R.G.M (Bureau of Geological and Mining Research) and the Directorate of Geology of the Ministry of Energy and Mines.

The main result of the studies was the discovery of the polymetallic deposit in 1984, it is the Douar HAJJAR deposit which is considered typical in terms of quantity in Africa. 
Geophysical methods used in the region have shown their effectiveness in the identification of mineralized sulphide body.

This set of data is studied and analyzed to provide a 2D and 3D ore body close model.

Geographic location: -

* The Hajjar deposit is located at $35 \mathrm{~km}$ southwest of Marrakech (Fig. 1). We reached by the secondary road $\mathrm{N}^{\circ}$ 507 linking Marrakech to Amezmiz.

* The morphology of the area is relatively moderate, manifested by some hills with elevations ranging from 400 to $800 \mathrm{~m}$.

* The Guemassa sector, as most parts of the Haouz plain, is characterized by an arid climate, hot in summer, cold and dry in winter.

Geological framework (hibti m. 1993): -

Regionally: -

Lithostratigraphy: -

Lithostratigraphy: -

From major geological domains of Morocco, the Guemassa is in the field of Atlasso-mèsètien limited to the north by the fronts of thrusts, and south by the South Atlasic accident.

The Guemassa massive (Figure 2), which is divided into two areas (area of Guemassa strictly and N'Fis domain), has been the subject of a comprehensive study is based primarily on geological correlation between this area of one hand, and secondly JbiletRehamna, as well as the different outcrops and research of mining interest.

From the lithostratigraphic perspective, the field of Guemassa, strictly speaking (Northern Part of the middle fault), is characterized by the following lithological succession:

- Basic pelites;

- The flyschs;

- The black shales;

- Carbonates;

- The pelites at the top; 


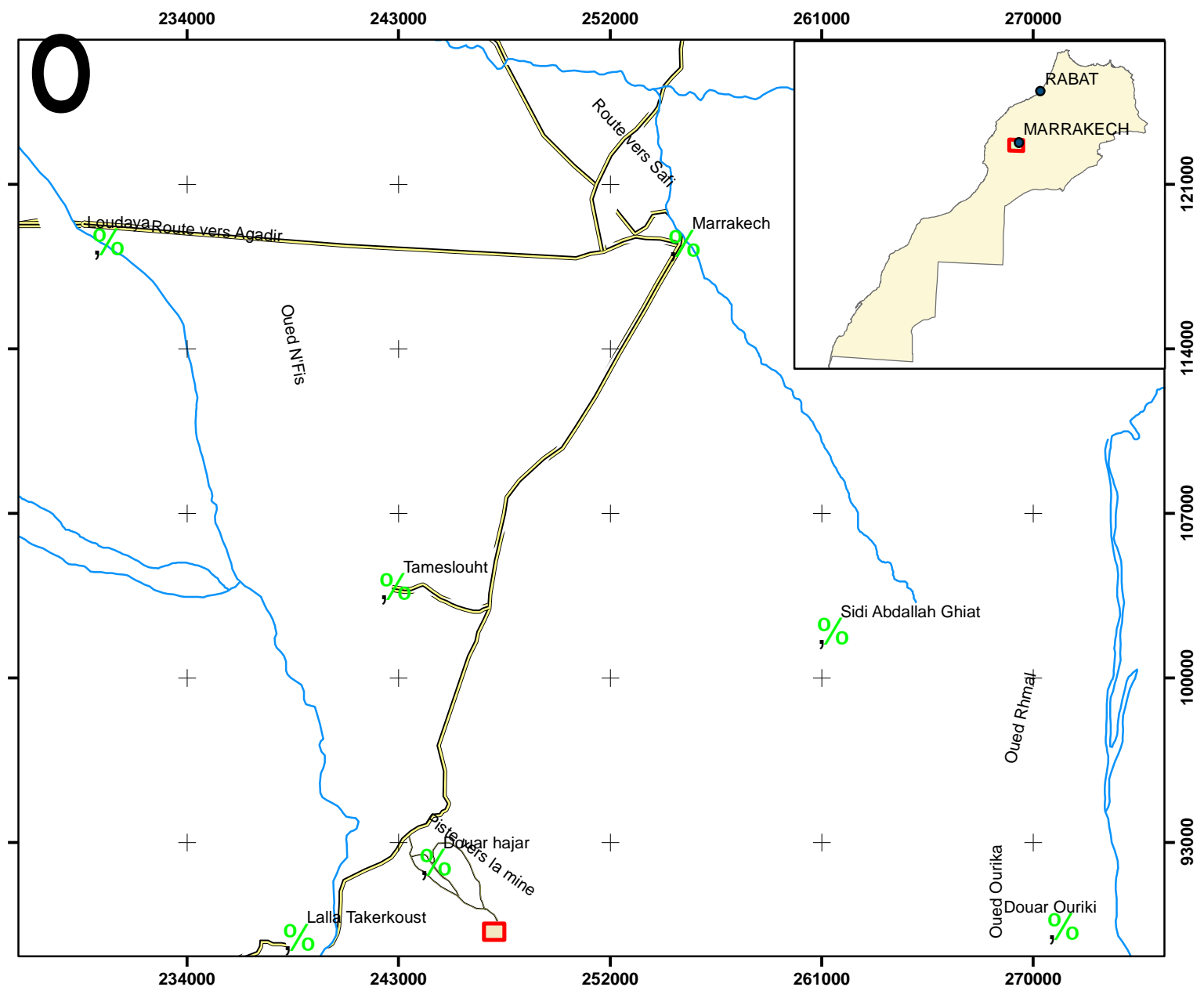

\section{Légend}

$\square$ Mine

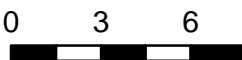

,\% Cities and Douar

Streams

\section{Roads}

\begin{tabular}{l}
$\overline{\overline{ }}$ Main road \\
\\
\hline Track
\end{tabular}

Figure 1:- Location map. 
N'Fis field, has a plurality of blocks (Amzough block, Oukhribane - Akhlig block, Imarine Block), each black is characterized by its own slightly different lithological succession of others.

For example, the block of Amzough which is a large synclinal structure, direction Northwest-Southeast, is formed from the bottom to top by:

- For Shale boards, alternating shale and sandstone;

- Alternating rhyolitic lavas and dissemination of sulfides;

- Alternating sandstone benches and organisms with calcareous benches.

The metal variety that contains this deposit is usually found in the massive state and it consists essentially of :

- $\quad$ Sphalerite (Zn S);

- Galena $(\mathrm{Pb} \mathrm{S})$;

- $\quad$ Chalcopyrite $\left(\mathrm{Cu} \mathrm{Fe} \mathrm{S}_{2}\right)$;

- $\quad$ Pyrite $\left(\mathrm{Fe} \mathrm{S}_{2}\right)$;

- Pyrrhotite $\left(\mathrm{Fe}_{(\mathrm{n}-1)} \mathrm{S}_{\mathrm{n}}\right)$;

This mineralization (Figure 3) based on a chimney, called stockwork, who had the role of supplier of clusters in metallic elements.

The roof of the minerals and the deposit of the wall have the following specific characteristics:

- The roof is characterized by the presence of arsenopyrite (FeAsS) and marcasite $\left(\mathrm{FeS}_{2}\right)$.

- The wall contains natural sediment exhalative (chlorite and biotite).

The cluster has the maximum power in its central-eastern part, while in the western part, we note intercalation of three levels of the orebody by altered sediments.

The uppermost unit, which is the roof of the mineralization is characterized by sedimentary formations whose succession, from bottom to top is as follows:

- Sandstone and limestone lenses past pyroclastic organizations;

- Laminated siltstones;

- Limestone and sandstone organizations brecciated past;

The set is covered by miopliocène and quaternary formations (Figure 4). 


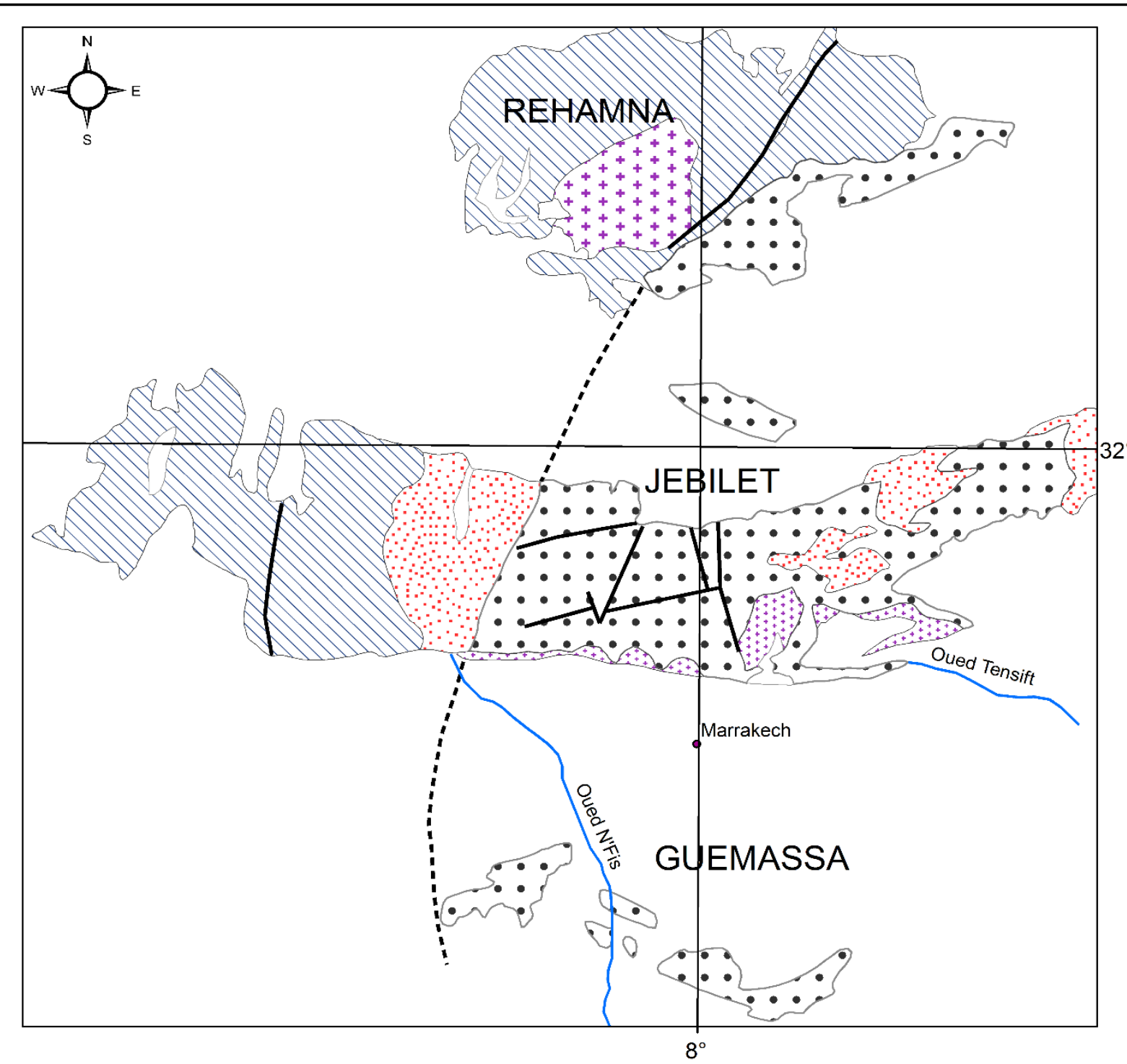

\section{Légende}

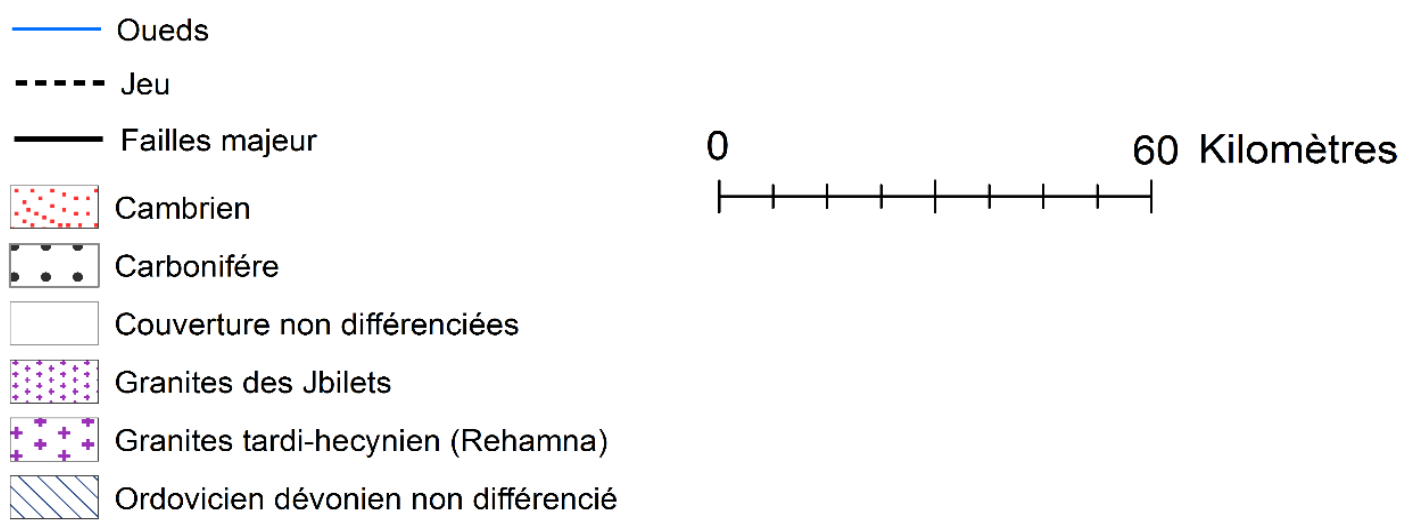

Figure 2:- Map of the geological situation in the region from CMG papers. 


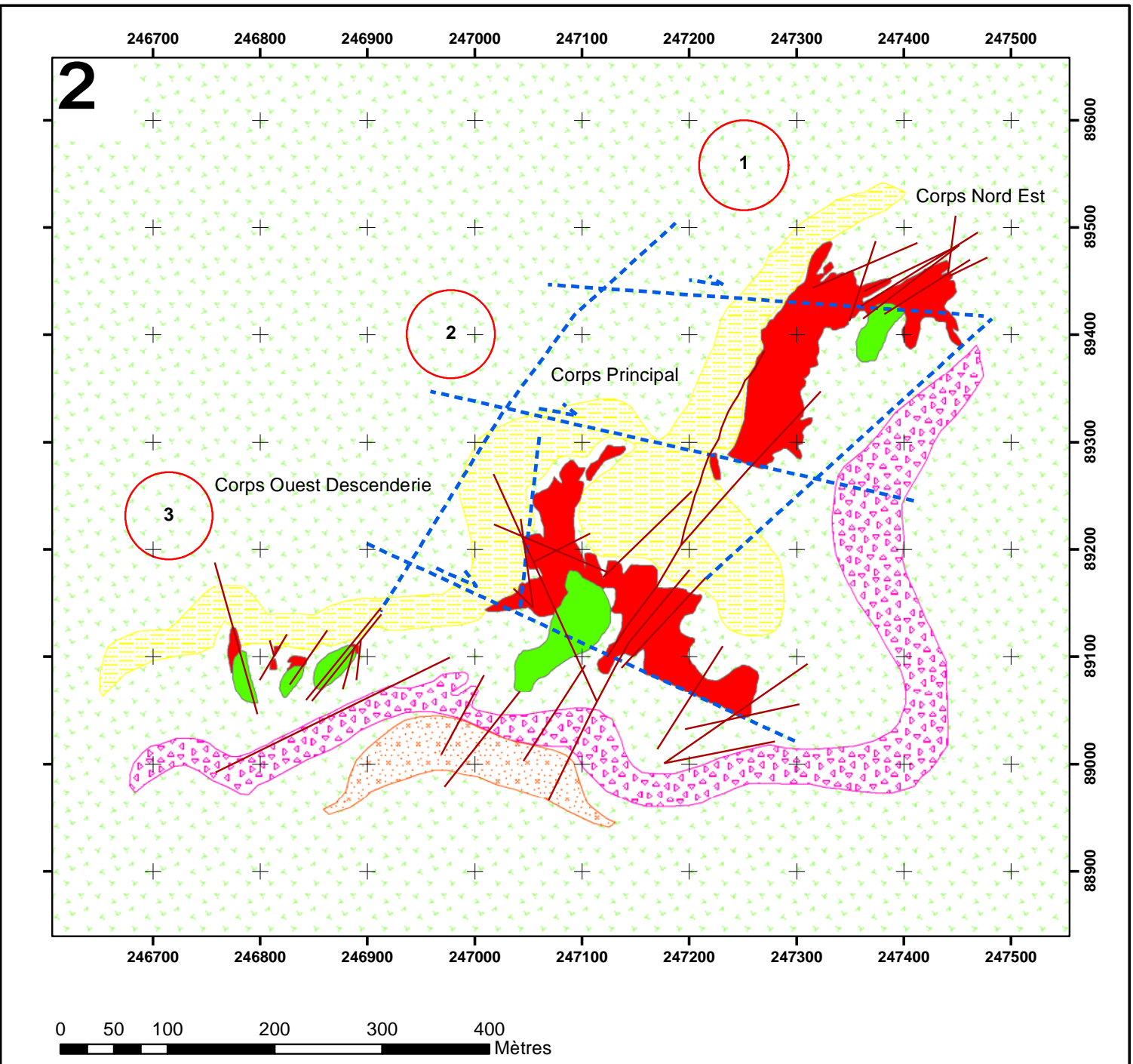

\section{Légende}

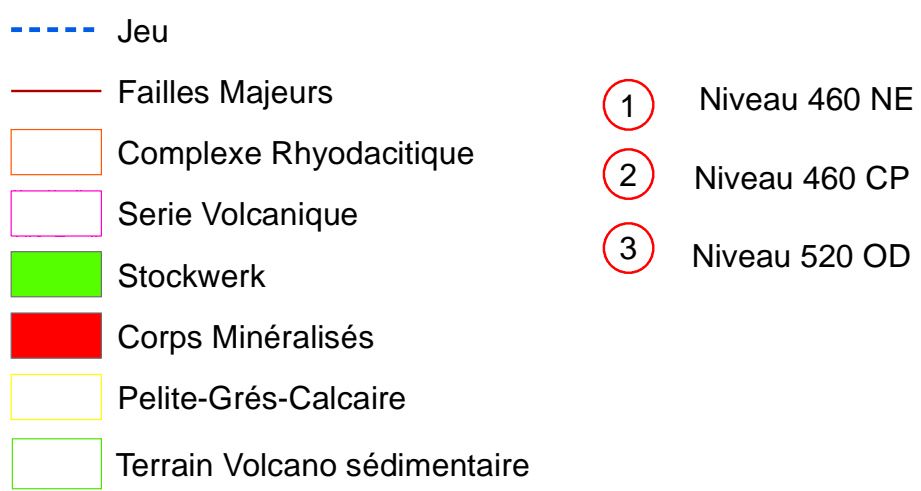

Figure 4: - Map of the Hajjar mineralization from CMG documents. 


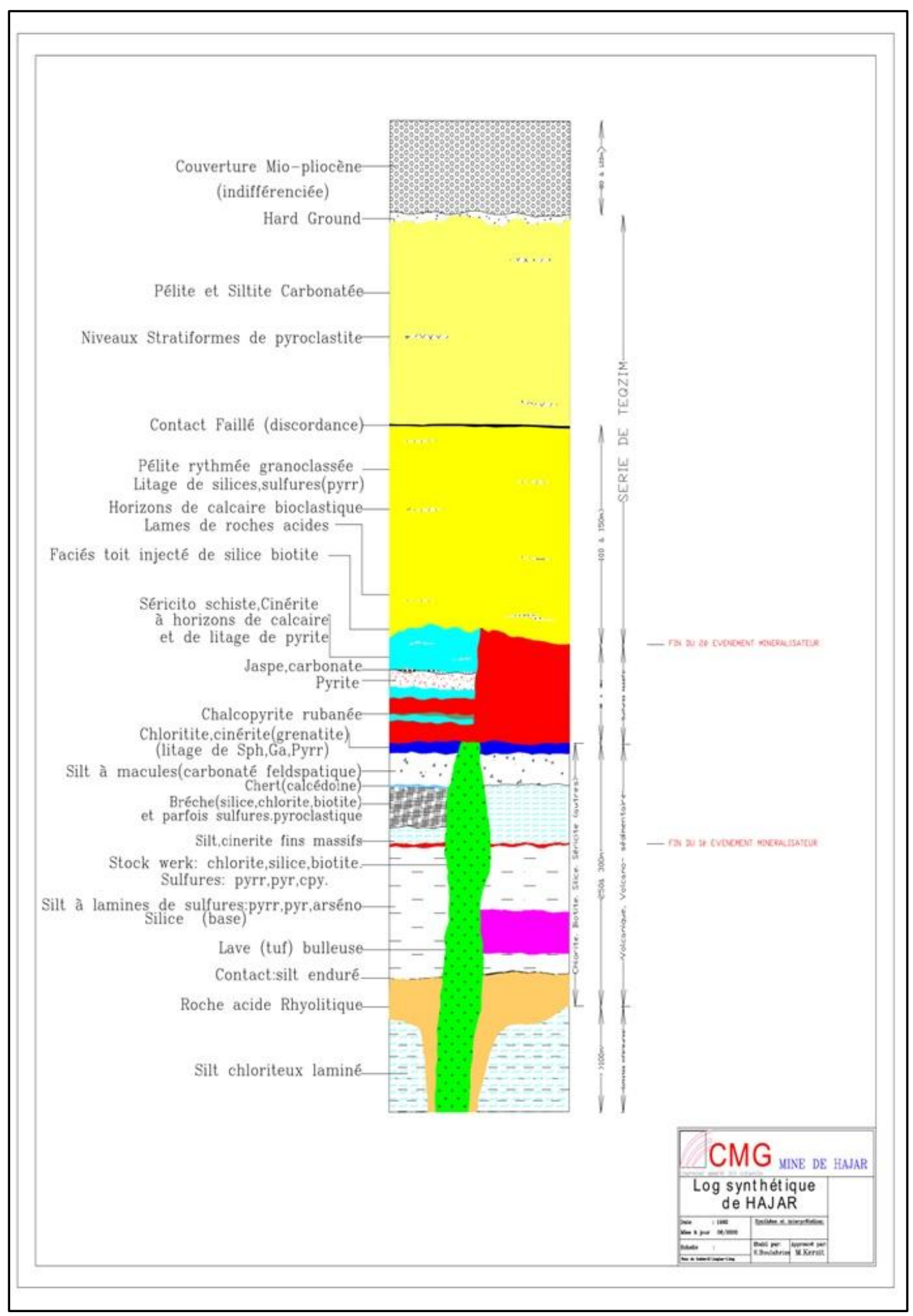

Figure 3:-Hajjar synthetic log from CMG Documents. 


\section{Gravimetric and magnetic survey at Hajjar: -}

Following the discovery by the HS1 well of Hajjarsulphide mineralization, a detail gravity and magnetic survey was carried out by the Geophysical Service of the Directorate of Geology in May 1984.

The anomaly related to this deposit is located plumb with an important plioquarternaire recovery from which emerge outcrops of Visean base consisting of stoneware disseminated pyrrhotite (Hathouti M. 1990).

Measurement campaign: -

The Hajjar area is $32 \mathrm{~km}$ long and $1.6 \mathrm{~km}$ wide. In total 10 profils (Fig. 5) were measured with a $25 \mathrm{~m}$ separation between the stations. The five profils located in the center of the area are spaced with $100 \mathrm{~m}$ and beyond is not doubled. The measurement of the gravity field has a profile of less compared to up the magnetic field. In total, we have arranged 1089 gravity measurements and 1210 magnetic measurements (Hathouti M. 1990).

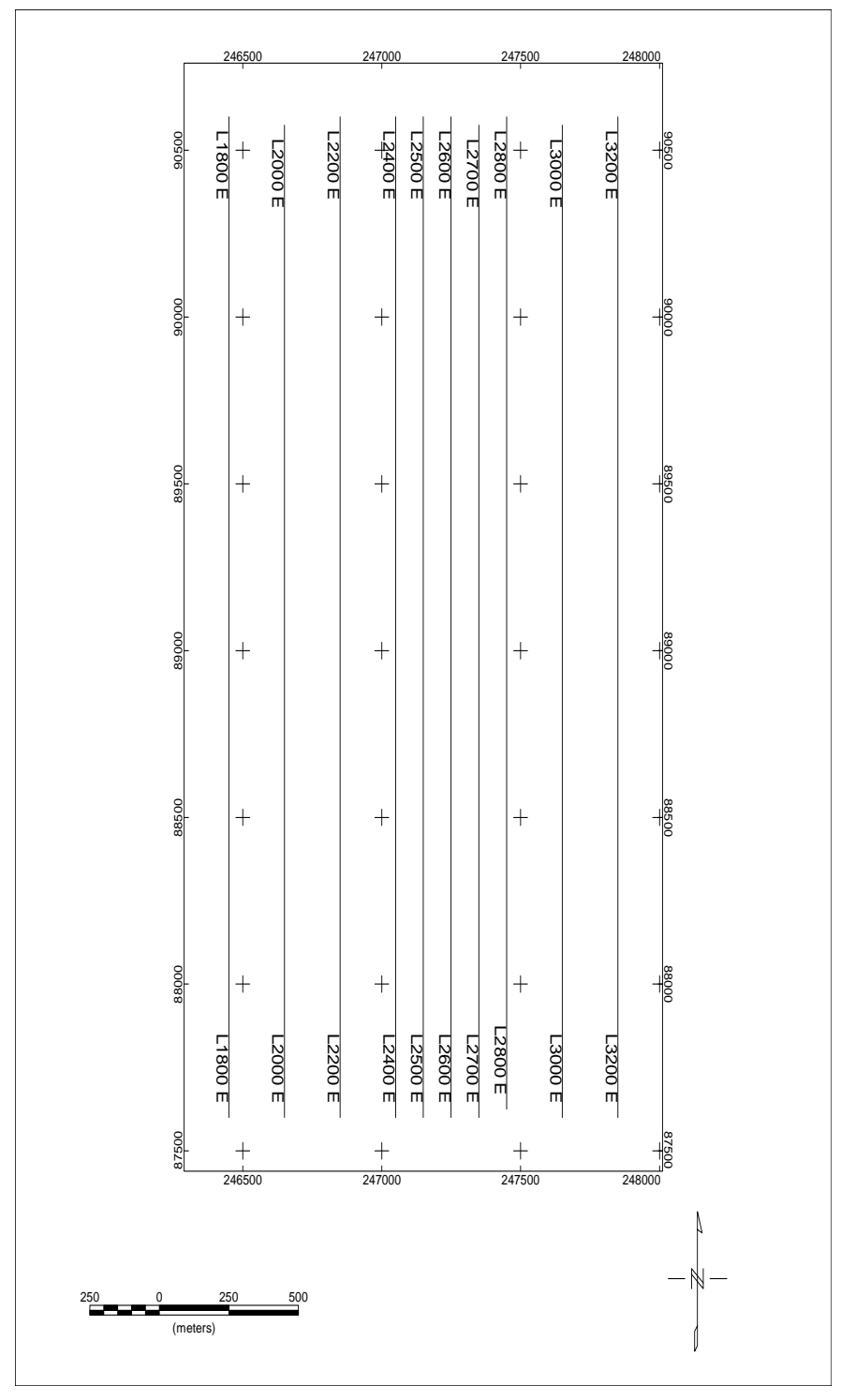

Figure 4:- Lines of gravity and magnetic surveys. 
Profiles and Magnetic Hajjarcards (Figure 6,7,8,9): -

The total magnetic field profils was dressed along the various measurelines to an inclination of $45^{\circ}$, and then the pole reduction was applied determine the orebody dip and its center, an inclination of $46^{\circ}$ and a declination of -7.40 ${ }^{\circ}$ are used to the magnetic pole reduction.

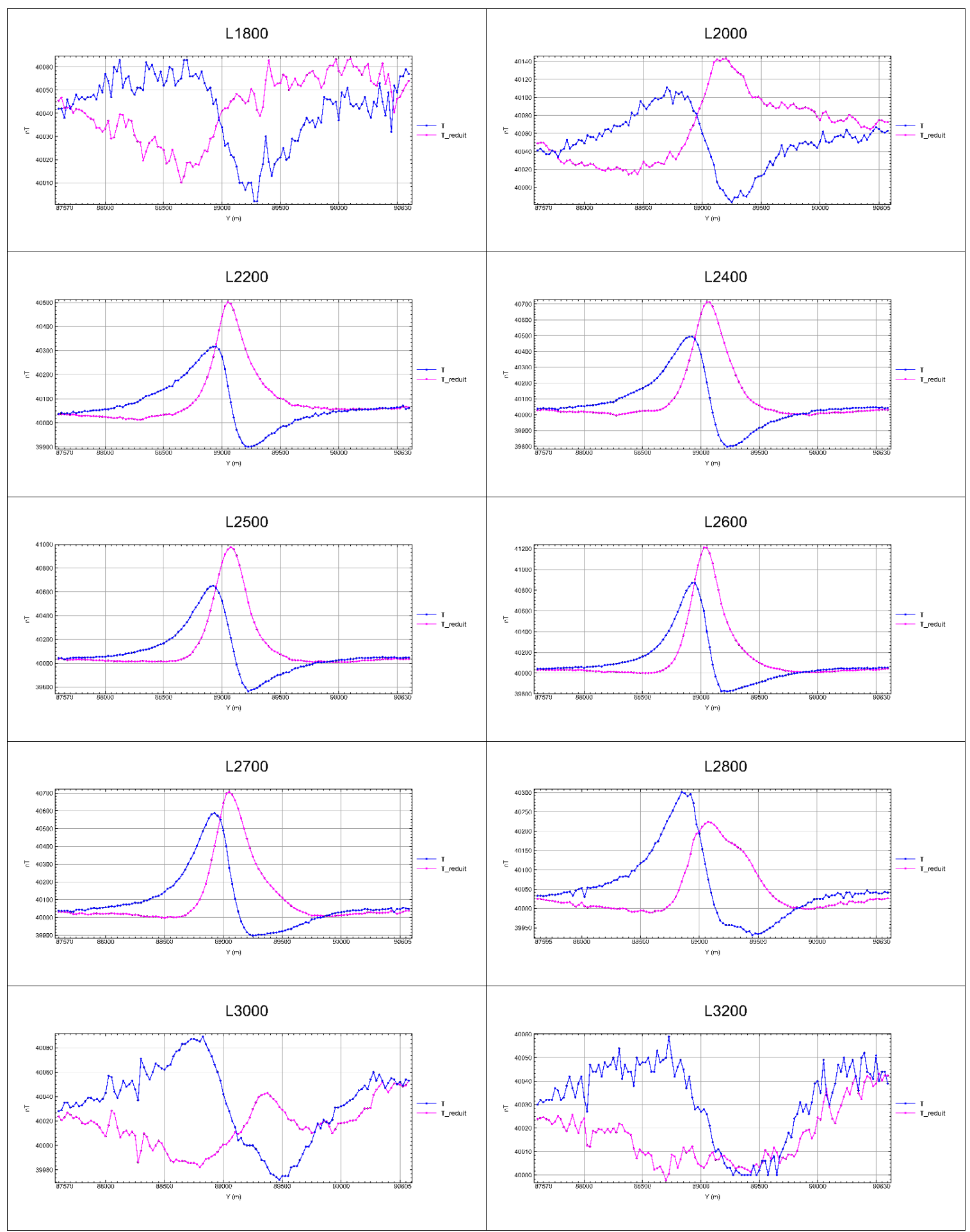

Figure 5:- Total field anomaly and total reduced anomaly of different profiles. 


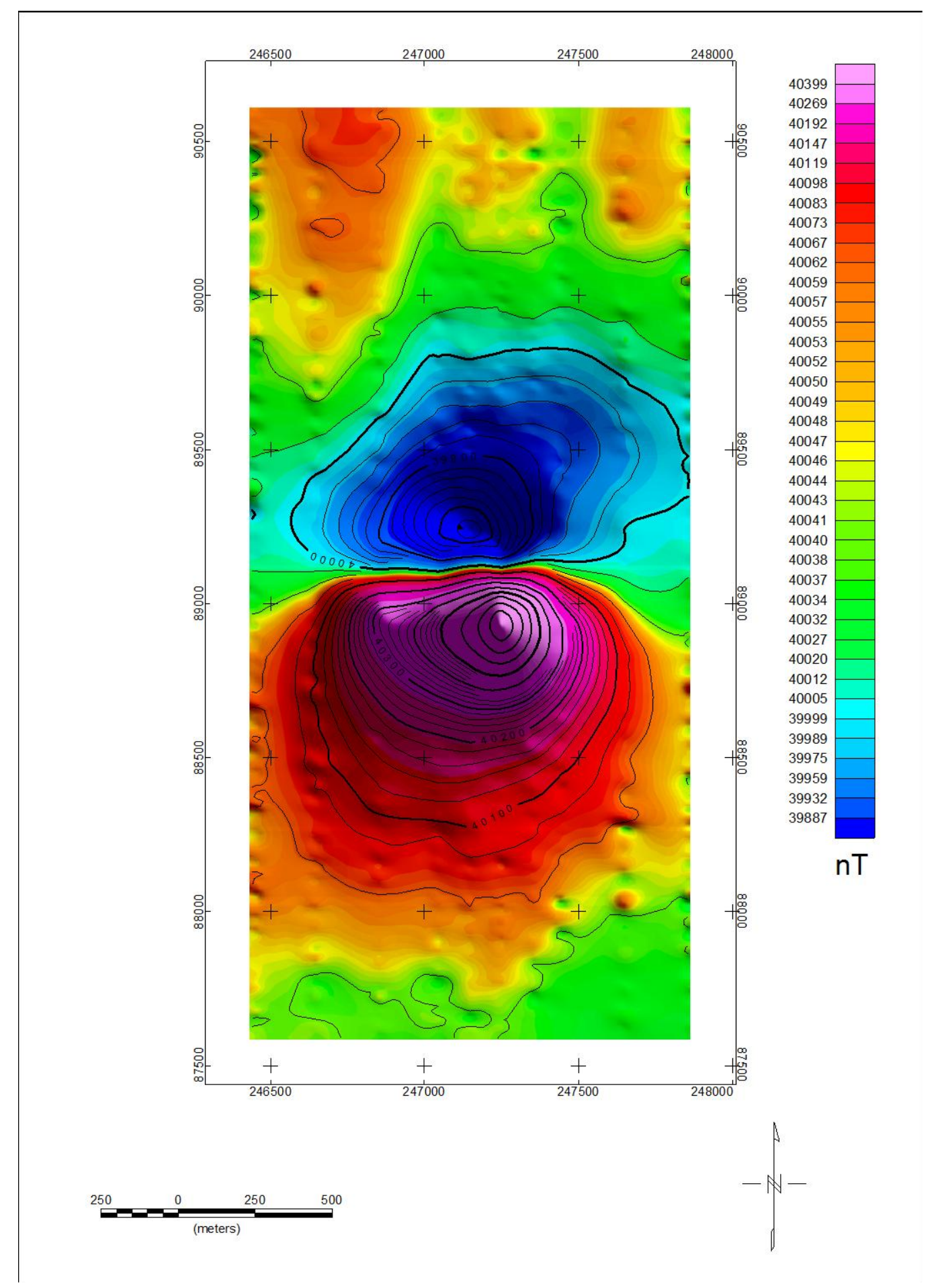

Figure 6:- Map of the total magnetic field. 


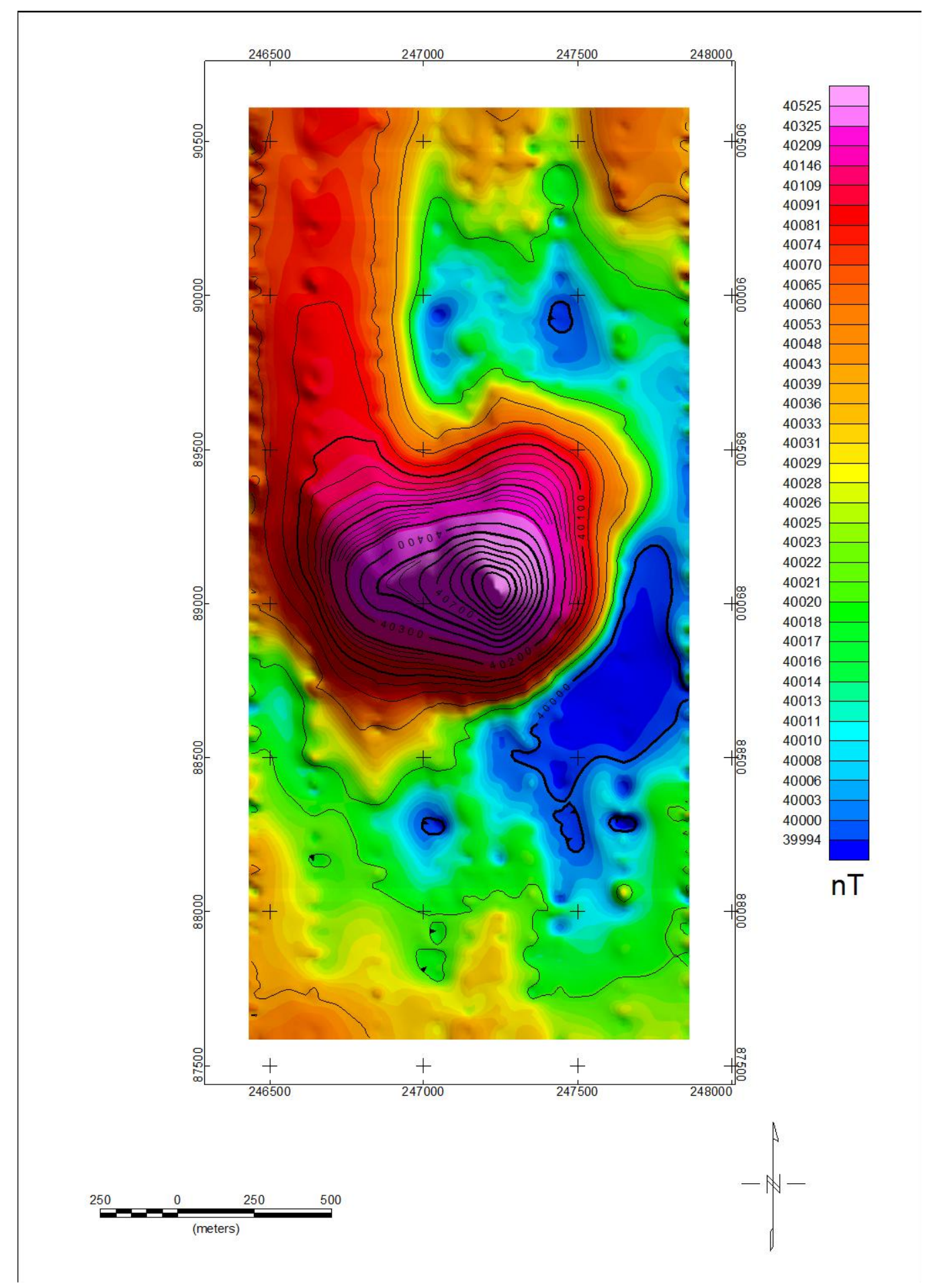

Figure 7:- Map of the pole reduction. 


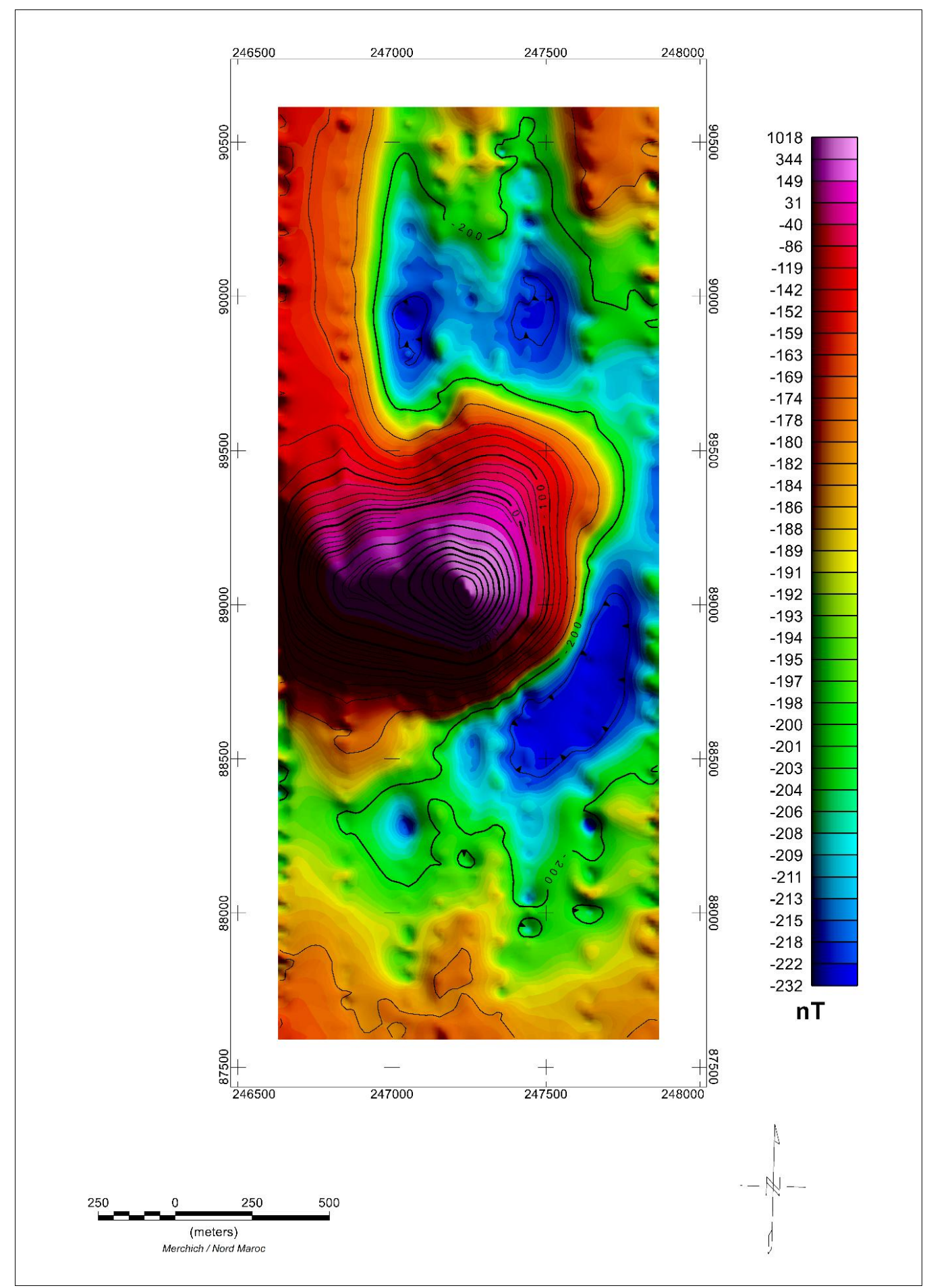

Figure 8:- Map of the Residual pole reduction. 


\section{Comment : -}

The Hajjarmagneticanomaly (Figure 7) is in bipolar form with a lowminimum in the North, and a strong maximum in the South. Its long axis of $1.4 \mathrm{~km}$ takes a direction E-W. It also notes from the magnetic card, that this anomaly is in a quiet magnetic context, which was a favorable factor for identification. In order to define the magnetic materials, we established a discount at the pole of total magnetic field (including anomaly figure) The parameters correspond to an inclination of the regional field $46^{\circ}$, declination is taken to be $7.40^{\circ}$ (El maamar, 1985).

As Reduction, the pole support, tilt derivative also contributed to the identification of the central body, governed by a magnetic calm context the tilt derivative map contains noise reflected by the regional magnetic effect.

Tilt Derivative: -

The tilt derivative (Figure 9) and its total horizontal derivative are useful for mapping shallow basement structures and mineral exploration targets. The tilt derivative is defined as:

$$
\mathrm{TDR}=\tan ^{-1}\left(\frac{\mathrm{TDR}}{\mathrm{THDR}}\right)
$$

where VDR and THDR are first vertical and total horizontal derivatives, respectively, of the total magnetic intensity $\mathrm{T}$.

$$
\begin{gathered}
-\frac{\pi}{2} \leq \mathrm{TDR} \leq \frac{\pi}{2} \\
\operatorname{VDR}=\frac{\mathrm{dT}}{\mathrm{dz}} \\
\mathrm{THDR}=\sqrt{\left(\frac{\mathrm{dT}}{\mathrm{dx}}\right)^{2}+\left(\frac{\mathrm{dT}}{\mathrm{dy}}\right)^{2}}
\end{gathered}
$$

The total horizontal derivative of the tilt derivative is defined as:

$$
\text { HD TDR }=\sqrt{\left(\frac{d T D R}{d x}\right)^{2}+\left(\frac{d T D R}{d y}\right)^{2}}
$$

HD_TDR is in units of radians/distance 


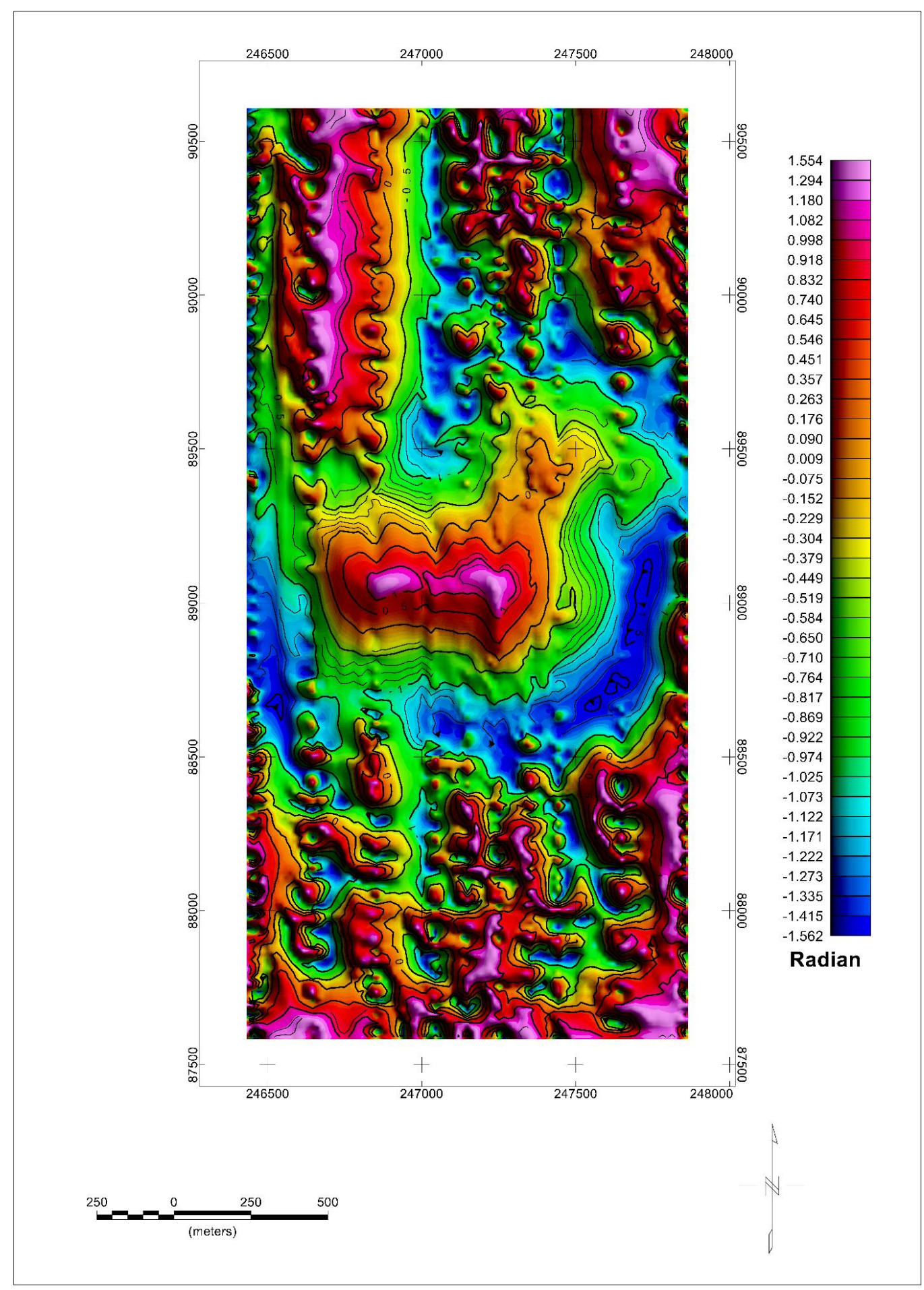

Figure 9:- The tilt derivative map. 


\section{Comment: -}

The tilt derivative Map (Figure 10) has developed available local scope central ore body. This allows the center location of the deposit with important intensities and resolution of signal.

Note that the extension of the central body signal is important, especially map shows the screen tilt derivative effect of the central body that implies the importance of the central body extent and the importance of its volume (reserve).

\section{Depth estimation: -}

To estimate the depth of a disturbing source we can use several methods. However, the most effective method is the Euler deconvolution.

Thompson (1982) has developed a particularly interesting method based on functions governing potential fields properties.

The method allows a precise sources location, anomalies origin on the horizontal plane and the estimation of their depth. rather general method since it assumes that few assumptions and can also be applied to gravity data as magnetic data.

P. Keating (1998) was interested in the problem of selecting solutions and particularly in the case of gravity data whose irregular distribution in general and thus affect the estimate the depth of the sources. To solve this problem and improve data interpretation, Asfirane et al. (2000), worked on synthetic models and showed that the Euler deconvolution method is very sensitive to the parameters choice involved in its implementation.

Based on a mathematical process represented by the so-called equation of Euler homogeneity, applying Euler deconvolution on magnetic and gravimetric anomalies enables the localization and determination of sources parameters and interference in the basement.

The application of this method on synthetic models has determined the correct structural index for each geometric shape. However, in reality, there is no geological body having a regular geometry but only an approach leads to better performance.

\section{Euler deconvolution: -}

Eulerian Deconvolution is a filtering method that allows the sources location of the faults. Either a magnetic source $\mathrm{S}$ at the point $\mathrm{M}$ of coordinates ( $\mathrm{x} 0, \mathrm{y} 0, \mathrm{z} 0$ ), The magnetic and gravimetric field observation point $\mathrm{P}$ is (Reid et al 1995, 2010 N. El Goumi.):

$$
\mathrm{T}(\mathrm{x}, \mathrm{y})=\mathrm{f}\left[\left(\mathrm{x}-\mathrm{x}_{0}\right),\left(\mathrm{y}-\mathrm{y}_{0}\right),\left(\mathrm{z}-\mathrm{z}_{0}\right)\right]
$$

Thompson (1982) showed that the homogeneity Euler equation can be written:

$$
\frac{\left(\mathrm{x}-\mathrm{x}_{0}\right) \partial \mathrm{T}}{\partial \mathrm{x}}+\frac{\left(\mathrm{y}-\mathrm{y}_{0}\right) \partial \mathrm{T}}{\partial \mathrm{y}}+\frac{\left(\mathrm{z}-\mathrm{z}_{0}\right) \partial \mathrm{T}}{\partial \mathrm{z}}=\mathrm{N}(\mathrm{B}-\mathrm{T})
$$

With

$\left(\mathrm{x}_{0}, \mathrm{y}_{0}, \mathrm{z}_{0}\right)$ : magnetic source position ;

$(\mathrm{x}, \mathrm{y}, \mathrm{z})$ : the observation point position ;

$\mathrm{T}$ : total field detected at $(\mathrm{x}, \mathrm{y}, \mathrm{z})$;

$\mathrm{B}$ : total regional value of the field;

$\mathrm{N}$ : degree of homogeneity often called structural index (SI) which characterizes the type of the source and the rate of change of field depending on the distance.

The principle of the method is based on the resolution of the equation with four unknowns: $\mathrm{x} 0, \mathrm{y} 0, \mathrm{z} 0$ and $\mathrm{B}$.

Structural indices are:

Table 1:- Structural index for geological models.

\begin{tabular}{|l|c|c|c|}
\hline \multicolumn{1}{|c|}{ Geological Model } & Number of Infinite dimensions & Magnetic SI & Gravity SI \\
\hline Sphère & 0 & 3 & 2 \\
\hline Pipe & $1(\mathrm{Z})$ & 2 & 1 \\
\hline Horizontal cylinder & $1(\mathrm{X}$ or $\mathrm{Y})$ & 2 & 1 \\
\hline Dyke & $2(\mathrm{Z}$ and $\mathrm{X}$ or $\mathrm{Y})$ & 1 & 0 \\
\hline Sill & $2(\mathrm{X}$ and $\mathrm{Y})$ & 1 & 0 \\
\hline Contact & $3(\mathrm{X}, \mathrm{Y}$ and $\mathrm{Z})$ & 0 & NA \\
\hline
\end{tabular}




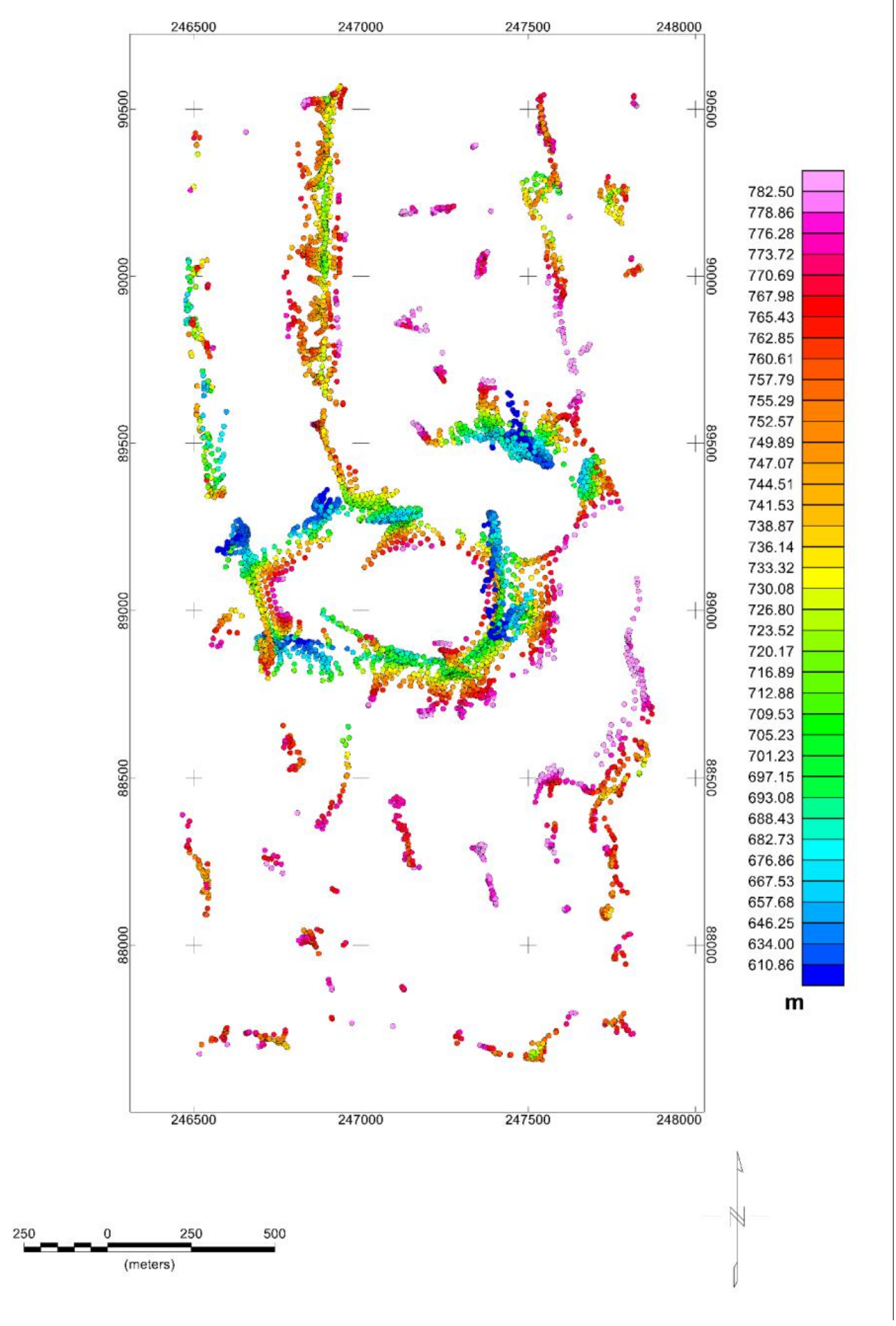

Figure 10:- Euler deconvolution map to $\mathrm{SI}=0$. 


\section{Comment: -}

Figure 11 shows the body depth map causing magnetic anomaly, according to our goal of determining the average depth of the roof of the mineralization, the overlay map of the residual anomaly and that of Euler solutions shows the alignment of the ore body with the center for past line, filtering solutions has eliminated invalid solutions

- $\quad$ Statistics of the Euler solutions:

$\checkmark$ Number of items: 5940

$\checkmark$ Number of dummies: 0

$\checkmark$ Minimum value: 610.86

$\checkmark$ Maximum value: 782.50

$\checkmark$ Mean value: 696.68

$\checkmark$ Standard deviation: 49.51

$\checkmark$ Arithmetic sum: 4315759.61

- The roof of the mineralization is to a depth of:

Note: -

$\checkmark$ Maximum - Moyenne - Standard déviation $=800-610.86-49.50 \sim-140 \mathrm{~m}$ from the surface.

Thus, for the verification of the results by other tools will be used for specific2D inversion magnetic data consoles. Apparent Susceptibility Calculation: -

A susceptibility filter is a compound filter that performs a reduction to the pole, downward continuation to the source depth, correction for the geometric effect and division by the total magnetic field to yield susceptibility. Apparent susceptibility mapping assumes a simple geometric model. The response is assumed to be caused by a collection of vertical, square-ended prisms of infinite depth extent, the horizontal dimensions of which are equal to the input grid cell size. This is an idealized approximation hence the descriptor Apparent.

$$
\begin{gathered}
\mathrm{L}(\mathrm{r}, \theta)=\frac{1}{2 \pi \mathrm{F} \cdot \mathrm{H}(\mathrm{r}) \cdot \Gamma(\theta) \cdot \mathrm{K}(\mathrm{r}, \theta)} \\
\mathrm{H}(\mathrm{r})=\mathrm{e}^{-\mathrm{hr}} \\
\Gamma(\theta)=\left[\sin \left(\mathrm{I}_{\mathrm{a}}\right)+\mathrm{i} \cos (\mathrm{I}) \cdot \cos (\mathrm{D}-\theta)\right]^{2} \\
\mathrm{~K}(\mathrm{r}, \theta)=\left(\frac{\sin (\text { a.r. } \cos (\theta)) \cdot \sin (\mathrm{a} \cdot \mathrm{r} \cdot \sin (\theta))}{\text { a.r. } \cos (\theta) \cdot \operatorname{a} \cdot \mathrm{r} \cdot \sin (\theta)}\right)
\end{gathered}
$$

I: Geomagnetic inclination in ${ }^{\circ}$;

D: Geomagnetic declination in ${ }^{\circ}$ azimuth;

h: Depth in ground units, relative to the observation level;

Ia: inclination for amplitude correction (never less than I) Default is \pm 20 degrees. If |Ia| is specified to be less than $|\mathrm{I}|$, it is set to I;

a: $1 / 2$ Cell size.

The susceptibility filter operator calculates the apparent magnetic susceptibility of the magnetic sources using the following assumptions:

- The IGRF has been subtracted from the input magnetic field prior to filtering;

- There is no remanent magnetization;

- All magnetic response is caused by a collection of vertical, square-ended prisms of infinite depth extent;

- The resulting susceptibility data is in SI units.

The validity of the results is naturally subject to how well the actual observed field conforms to these assumptions.

If a date is entered to calculating the inclination and declination, and if the grid does not have a coordinate system assigned, you will be prompted to defined it. IGRF date and parameters, once defined, become the values used in other controls that require them. The field strength is only required for apparent susceptibility calculation, but is recalculated along with the inclination and declination in the other controls, so the values are always synchronized. 


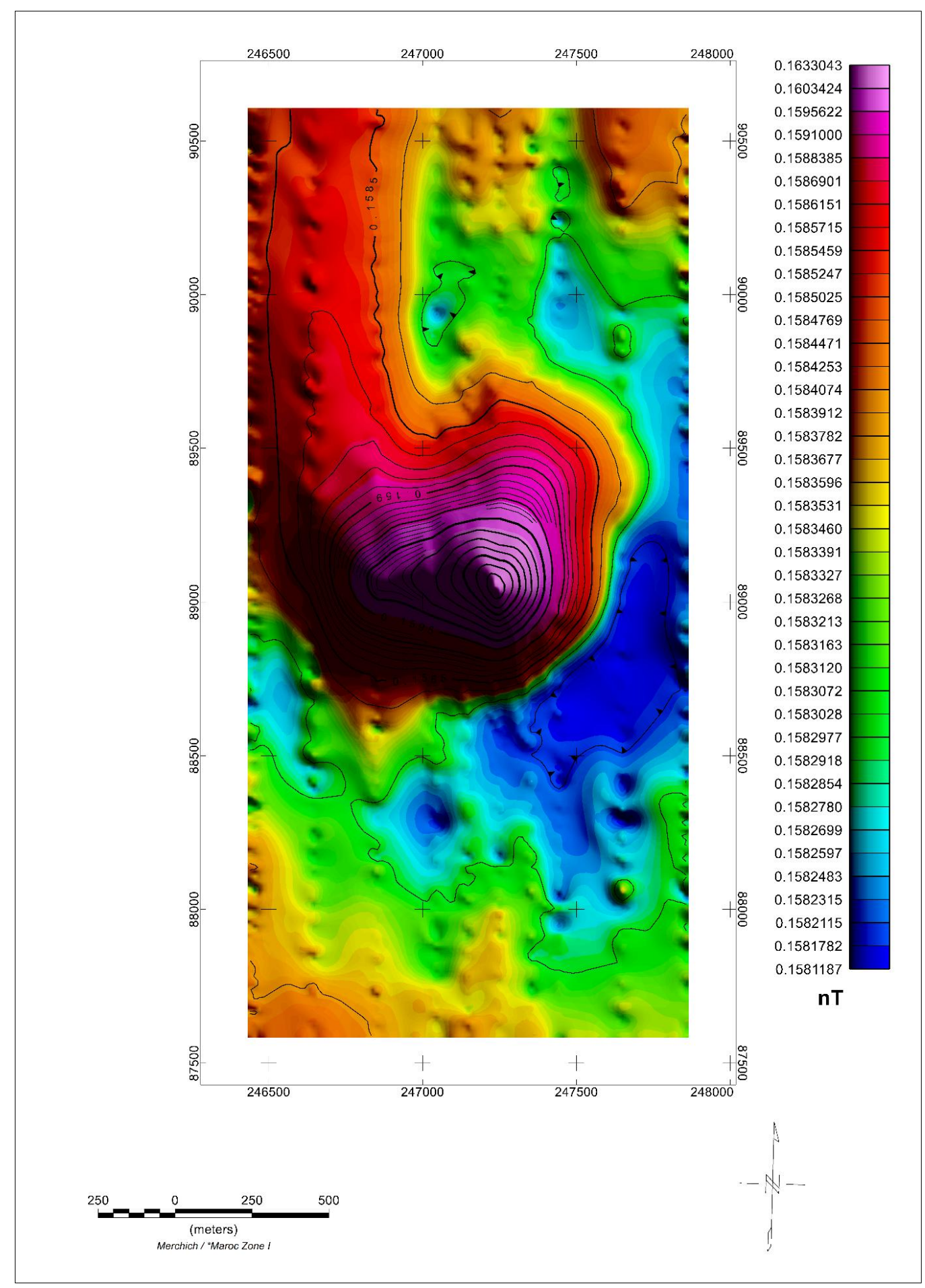

Figure11:- Map of the lateral susceptibility distribution. 
According to the lateral susceptibility distribution map (Figure 11) shows a variation of susceptibilitybetween 0.1581187 to $0.1633043 \mathrm{nT}$ localized essentially in the main body, with a significant extent. This susceptibility confirms the existence of a verysusceptiblepolymetallic ore and which consists of (Farhan A., B. Souni 1999):

- $10 \%$ of Zinc;

- $3 \%$ Lead;

- $1 \%$ Cooper:

- $30 \%$ of sulfur;

- $75 \mathrm{~g} / \mathrm{t}$ silver.

\section{D Inversion: -}

Inversion can be defined as a procedure for obtaining subsurface models that may adequately describe an observed data set. In the case of geophysical data, our observations consist of what might be called the physical signature of a subsurface structure: the structure's reflected (or scattered) wave field due to excitation by a structure's anomalous gravity or magnetic field, etc. The theoreticalfoundationsfor modern inverse theorycanbefound in theearlyworkofBackusand Gilbert (1967, 1968, and 1970).

Inversion or "inverse modeling" attempts to reconstruct subsurface features from a given set of geophysical measurements, and to do so in a manner that the model response "fits" the observations according to some measure of error. Hence, the choice of a "good" model is crucial. Even assuming that our choice of model is adequate, numerous problems still remain. In fact, Jackson (1972) has aptly described inversion as the "interpretation of inaccurate, insufficient, and inconsistent data."

The observed and the theoretical geophysical responses are matched by the use of a suitable optimization algorithm. All such algorithms are designed to minimize some measure of the difference between the observed and the computed data. Most schemes start out with an initial guess of the model parameters, from which an initial model response. In the next step, the optimization algorithm yields a set of adjusted or updated parameter estimates. These updated parameters are then "plugged" into the theoretical model, and the resulting new theoretical response should produce (hopefully) an improved match to the data. If this happens, the inversion bis said to converge; if not, there are numerous means to achieve convergence, althoughn one of the known methods is fool proof. Because the model response is generally a non linear function of the model parameters, it is necessary to do these calculation site ratively; that is, the above procedure must be applied many times in succession until a satisfactory degree of agreement between the theoretical and the recorded magnetic responses has been achieved.

During inversion modelling, The software automatically adjusts nominated model parameters so as to improve the similarity of the observed and calculated field. This involves minimising the root-mean-square (RMS) difference between the observed and calculated field profiles (Profile and Down hole modes) or between the observed and calculated field images (Map mode). By default the software will execute 100 inversion iterations (or it will stop when no further improvement in "fit" is obtained). During inversi on the RMS difference between the observed and calculated profiles is displayed in the status bar at the bottom of the main Potent $Q$ window.

After inverting it is often useful to adjust the background field and invert again. Similarly, we might decide to fix certain parameters (by unchecking their Invert boxes) and continue inverting. 


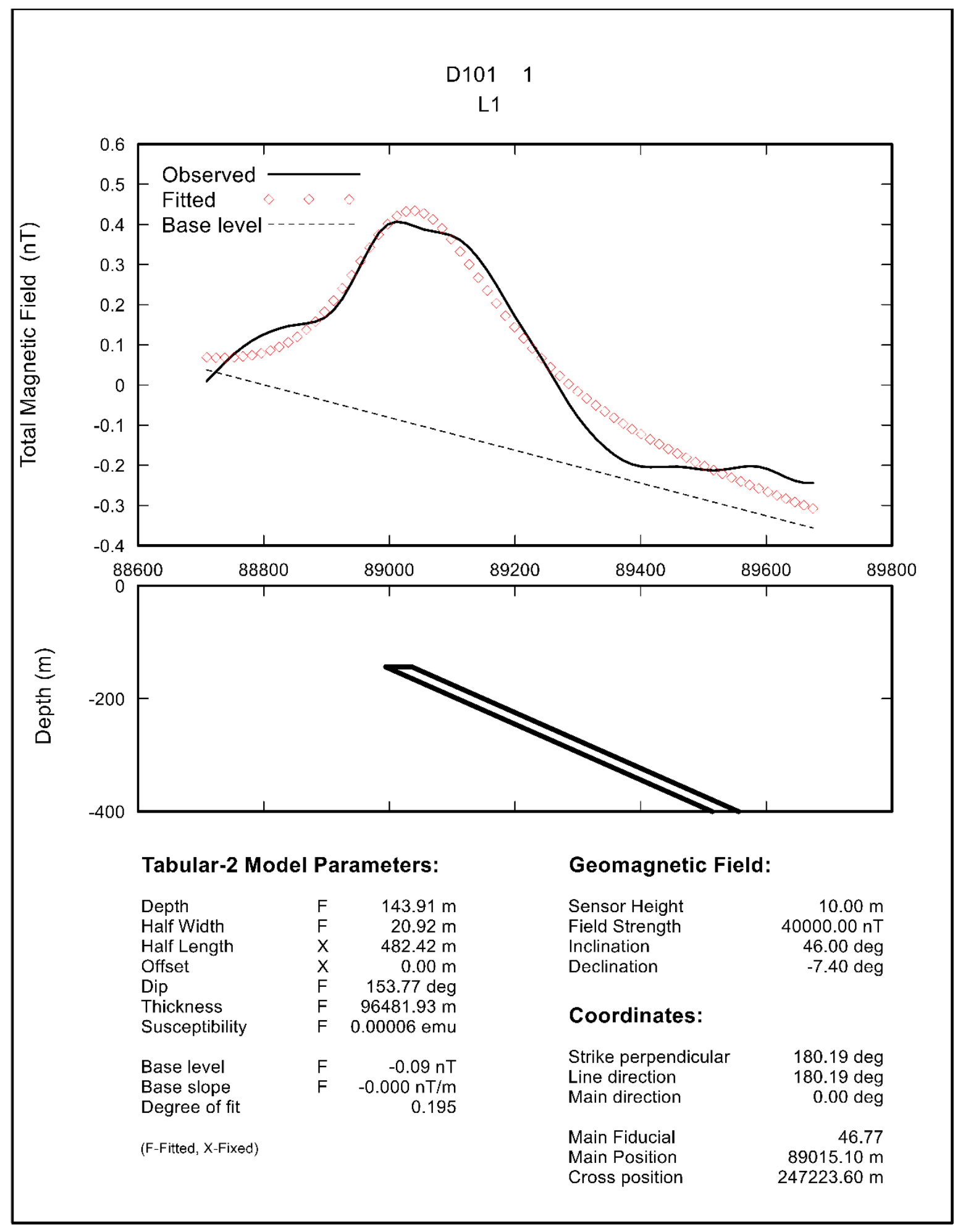

Figure 12:- First inversion of the central profile 


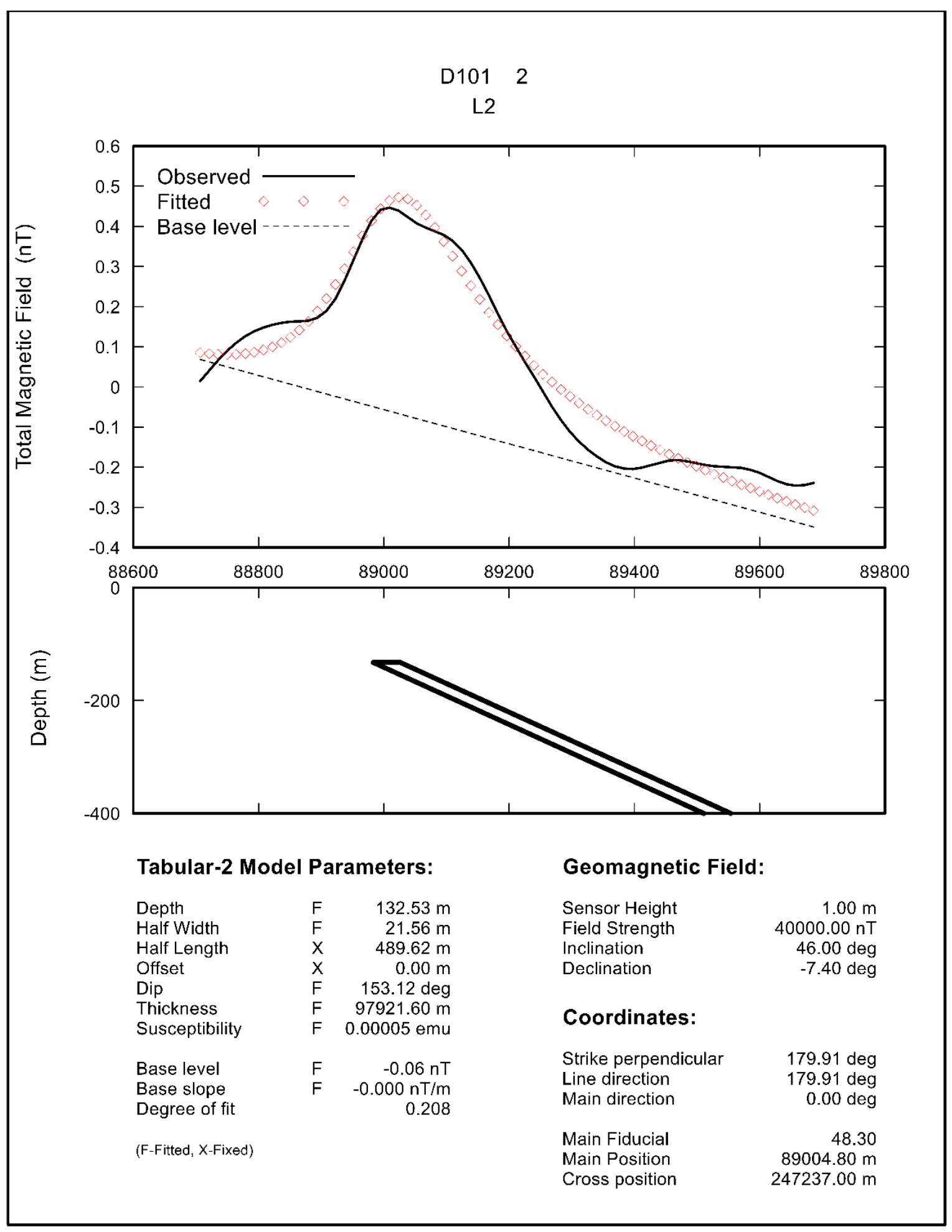

Figure 13:- Second inversion of the central profile 


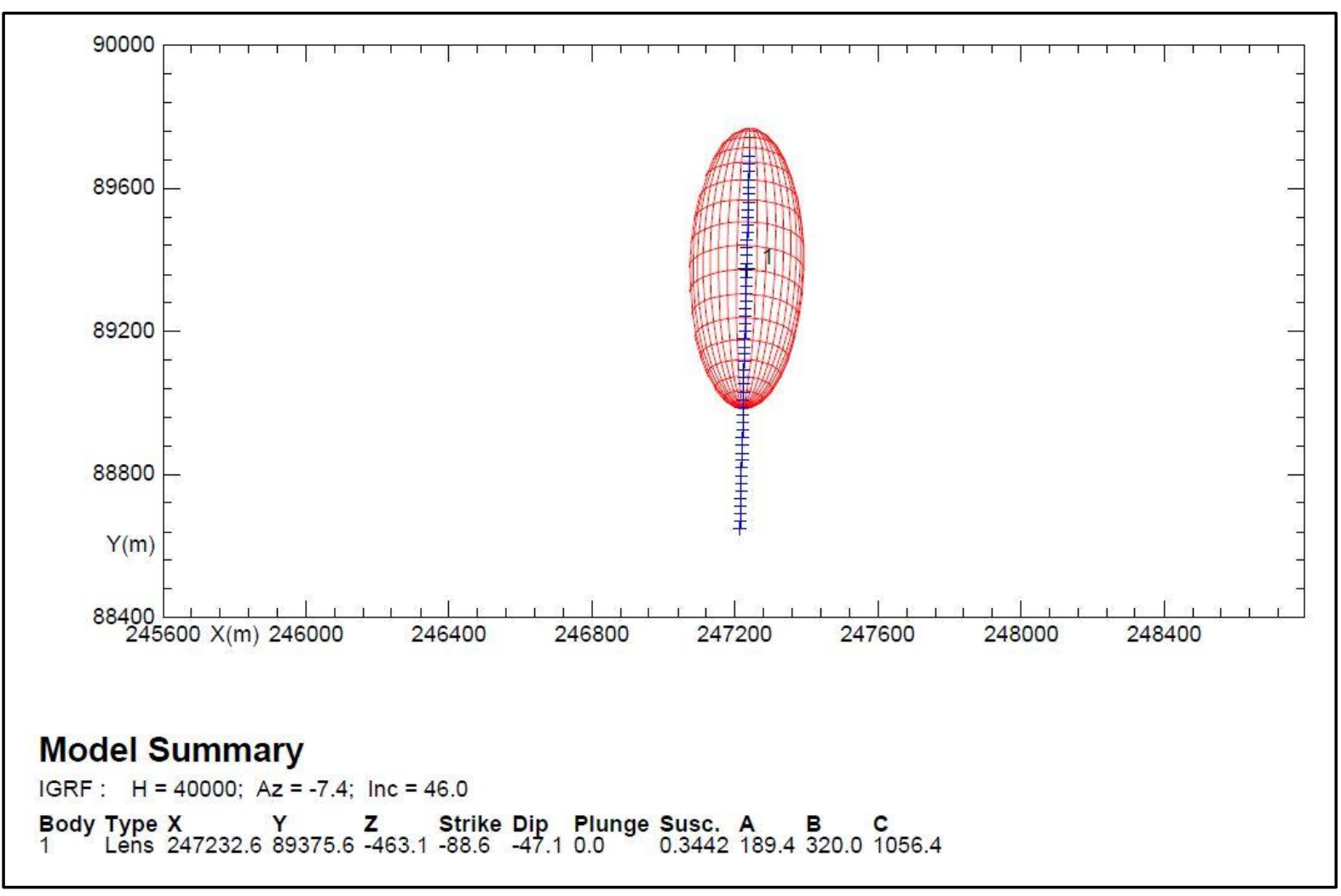

Figure 14:- Inversion of the central profileby potentQ $(\mathrm{X}, \mathrm{Y})$.

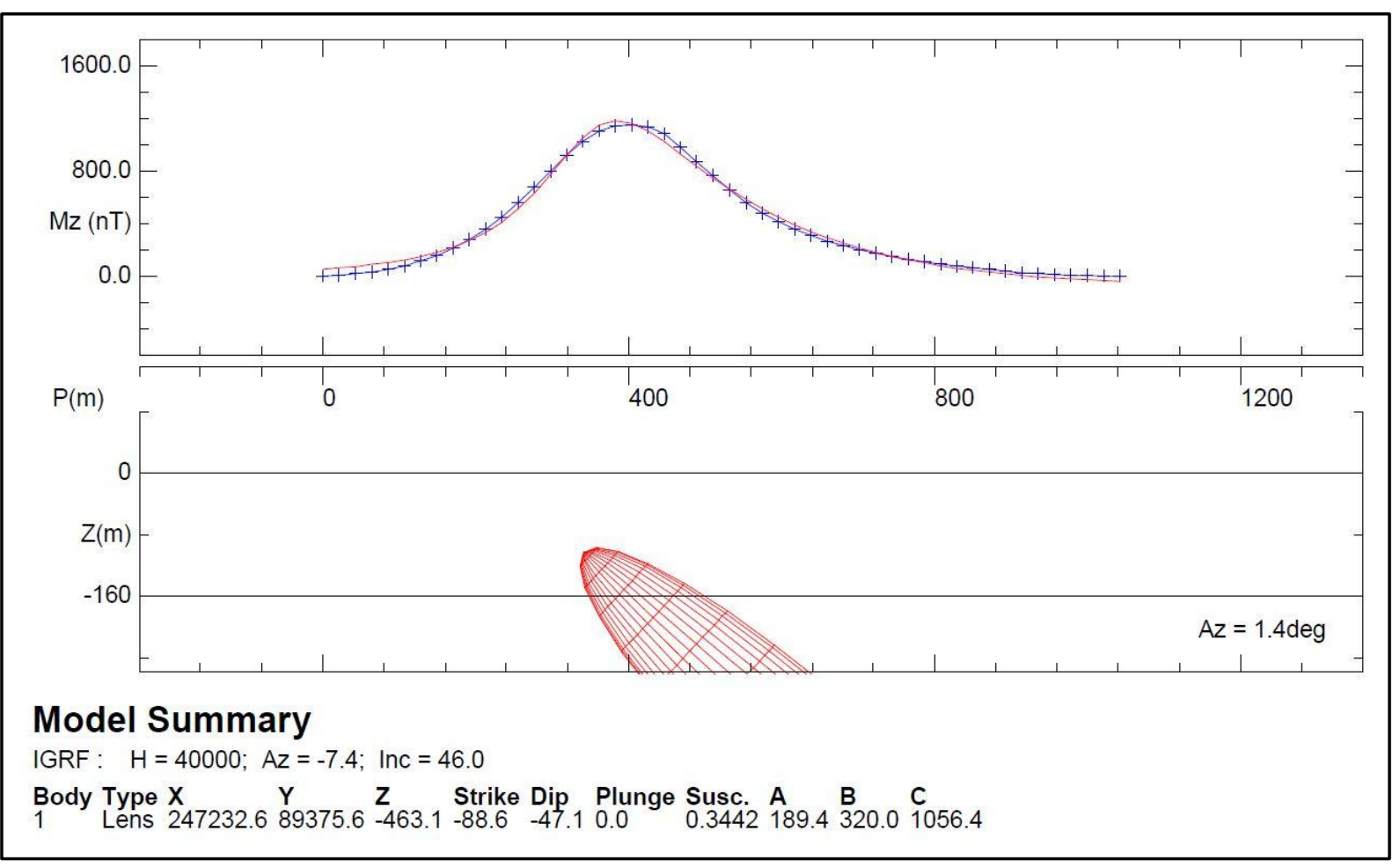

Figure 15:- Inversion of the central profile bypotentQ (Y, Z). 


\section{Comment: -}

The results of the inversion are enabled the elaboration of two different 2D models consoles (Fig 13,14,15,16), the first (Fig 13,14) is specific for ribbon (Dyke), and second (PotentQ: Fig 15,16) is specific for Lens, the purpose of the use of two different consoles is the confirmation of the depth $(143 \mathrm{~m})$, tilt, extension (A, B, C), susceptibility $(0.35 \mathrm{nT})$, Dip $\left(45^{\circ}\right)$, factorial parameters for the target definition, the parameters were defined at the bottom of figures.

\section{DModeling: -}

\section{Forward model theory: -}

It is possible to calculate the model gravity or magnetic effect whose parameters are known as: the dimensions (the extension and thickness) and density orsusceptibility (or density, susceptibility contrast). We will develop here only the 3-D modeling of a rectangular prism (Abdelfettah Y. 2009). Its use is, of course, possible for two-dimensional case. Just then consider an infinite horizontal direction. By equation (12), one can calculate the gravimetric attraction ormagnetic effectof a bluff body (origin of the anomaly) with coordinates $\mathrm{x}$ ', $\mathrm{y}$ ' and $\mathrm{z}$ 'remote observation point $\mathrm{P}(\mathrm{x}, \mathrm{y}, \mathrm{z})$ for $\mathrm{r}$ by:

$$
g(x, y, z)=-G \int_{z^{\prime}} \int_{y^{\prime}} \int_{x^{\prime}} \delta\left(x^{\prime}, y^{\prime}, z^{\prime}\right) \frac{z-z^{\prime}}{r^{3}} d x^{\prime} d y^{\prime} d z^{\prime}
$$

Where( $\mathrm{r}$ ) is the distance between the measuring point and the body is:

$$
r=\left(\left(x-x^{\prime}\right)^{2}+\left(y-y^{\prime}\right)^{2}+\left(z-z^{\prime}\right)^{2}\right)^{1 / 2}
$$

The relation (12) can be written:

$$
g(x, y, z)=\int_{z^{\prime}} \int_{y^{\prime}} \int_{x^{\prime}} \delta\left(x^{\prime}, y^{\prime}, z^{\prime}\right) \psi\left(x-x^{\prime}, y-y^{\prime}, z-z^{\prime}\right) d x^{\prime} d y^{\prime} d z^{\prime}
$$

With $\psi$ is the Green's function and is calculated by:

$$
\psi(\mathrm{x}, \mathrm{y}, \mathrm{z})=-\mathrm{G} \frac{\mathrm{z}}{\left(\mathrm{x}^{2}+\mathrm{y}^{2}+\mathrm{z}^{2}\right)^{3 / 2}}
$$

It reflects the gravity attraction or magnetic effect at $\mathrm{P}$ of the bluff body. By the principle of superposition, the overall gravitational or magnetic effect will be the sum of all the effects of each geometric body. The total gravimetric attraction or magnetic effect at the measurement point $m$ is given by:

$$
\mathrm{g}_{\mathrm{m}}=\sum_{\mathrm{n}=1}^{\mathrm{N}} \delta_{\mathrm{n}} \psi_{\mathrm{mn}}
$$

When $\delta \mathrm{n}$ is the density or susceptibility of the $\mathrm{n}$ th and geometry is $\psi_{\mathrm{m} n}$ gravimetric attraction or magnetic effect of the nth geometry $\mathrm{m}$ is the measurement point. To model a complex structure, it is necessary to cut it into prisms.

Whereas a rectangular prism shown in Figure 17. The gravity attraction ormagnetic effectmeasured at $\mathrm{P}$ back to the origin is given by (Blakely 1995):

Or

$$
\mathrm{g}=\mathrm{G} \delta \sum_{\mathrm{i}=1}^{2} \sum_{\mathrm{j}=1}^{2} \sum_{\mathrm{k}=1}^{2} \mu_{\mathrm{ijk}}\left[\mathrm{z}_{\mathrm{k}} \arctan \frac{\mathrm{x}_{\mathrm{i}} \mathrm{y}_{\mathrm{j}}}{\mathrm{z}_{\mathrm{k}} \mathrm{R}_{\mathrm{ijk}}}-\mathrm{x}_{\mathrm{i}} \log \left(\mathrm{R}_{\mathrm{ijk}}+\mathrm{y}_{\mathrm{j}}\right)-\mathrm{y}_{\mathrm{j}} \log \left(\mathrm{R}_{\mathrm{ijk}}+\mathrm{x}_{\mathrm{i}}\right)\right]
$$

$$
\begin{aligned}
& \mathrm{R}_{\mathrm{ijk}}=\sqrt{\mathrm{x}_{\mathrm{i}}^{2}+\mathrm{y}_{\mathrm{j}}^{2}+\mathrm{z}_{\mathrm{k}}^{2}} \\
& \mu_{\mathrm{ijk}}=(-1)^{\mathrm{i}}(-1)^{\mathrm{j}}(-1)^{\mathrm{k}}
\end{aligned}
$$


The relation (3), thus calculates the gravity attraction or magnetic effect of a complex model. To avoid the effects of the instrument, it is possible to add a medium (1-D) to the edges of the main model. In practice, the medium (1-D) is extended until $\infty$ that there is greater effect on action points. In the vertical direction, the medium (1-D) is not needed, it only adds a constant.

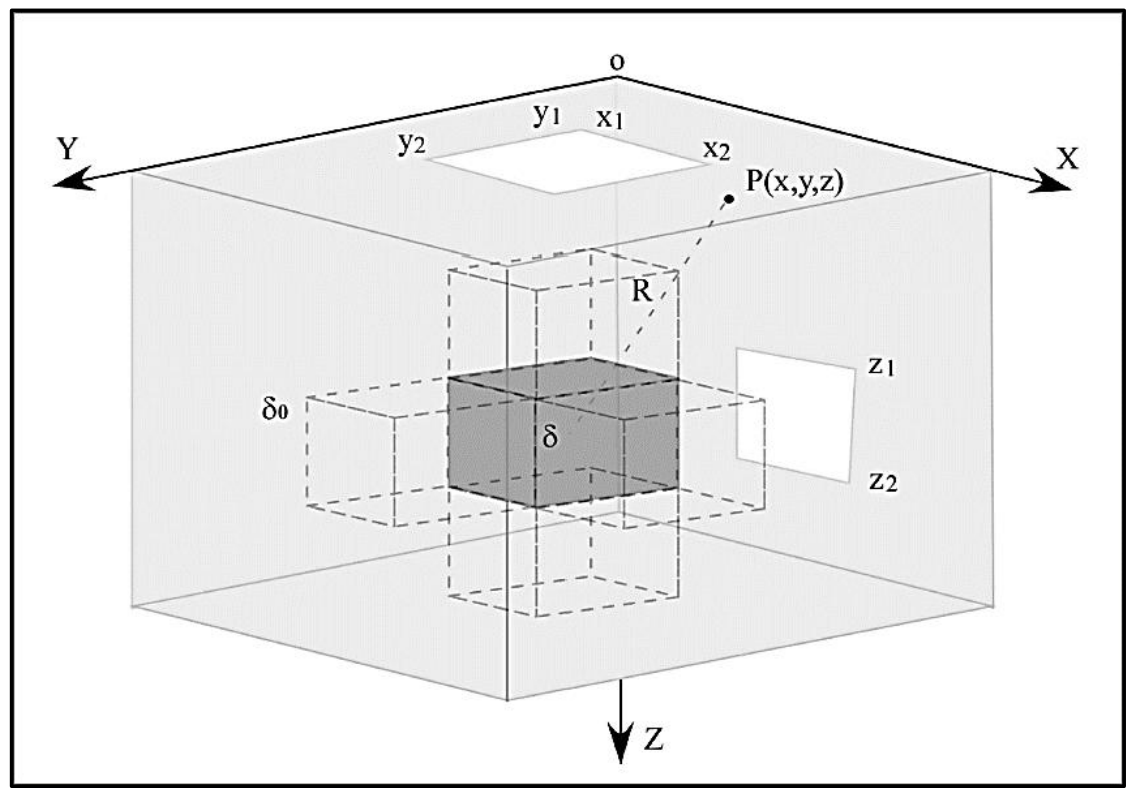

Figure 16:- Presentation of an elemental prism for the gravitational attraction or magnetic effect calculation of the body dimension $\mathrm{x} 1 \leq \mathrm{x} \leq \mathrm{x} 2, \mathrm{y} 1 \leq \mathrm{y} \leq \mathrm{y} 2$ et $\mathrm{z} 1 \leq \mathrm{z} \leq \mathrm{z} 2$ of $\delta$ density, distant from $\mathrm{R}$ measured point.

\section{Development of the forward model: -}

\section{Three-dimensional geological modeling (FOUDIL-BEY N.): -}

By definition geological modeling is a geometrical representation of an object present in the basement. A geological model can be represented numerically by a geometric shape using the computer tool, but it is difficult to find a definition of the geological model word for its definition varies from one specialty to another (Massot 2002). Indeed, in geophysics we tend to represent the basement by allocating physical properties (density, velocity, magnetization, etc.) in a grid more or less regular in 2 or 3 dimensions. In contrast to a three-dimensional geological model we will represent the basement of a set of geometries (fault horizon anticline, etc.). Nevertheless, the purpose of the model is a simplified representation of the basement that helps in understanding and geophysical and geological interpretation, even the demonstration of natural mineral resources.

\section{Forward model: -}

Based on the theory of calculation of the model gravimetric or magnetic effect (Figure 17), forward modeling involves the creation of a hypothetical geological model and the calculation of the geophysical response of this model in the basement. The used tool (GM-SYS 3D) enables interactive manipulation of the model and the real-time calculation of gravity orsusceptibility. The calculation thus requires that the $\mathrm{x}$ component and the $\mathrm{y}$ component in the grid spacing in three dimensions are equal.

3D magnetic model generated from the following inputs: (Geometry grid $\backslash$ Top elevation grid $\backslash$ Base of model $\backslash$ Elevation Grid $\backslash$ Background susceptibility $\backslash$ Observed susceptibility values for the survey $\backslash$ Lateral distribution of susceptibility), is a three-dimensional volume sources with susceptibilities (Figures. 18, 19 and 20). This volume can be divided into secondary volumes having different properties to create a realistic representation of properties (susceptibility) distributions in the basement. We can set the weight to calculate the response of the model for specific susceptibility. The model is shown below: 


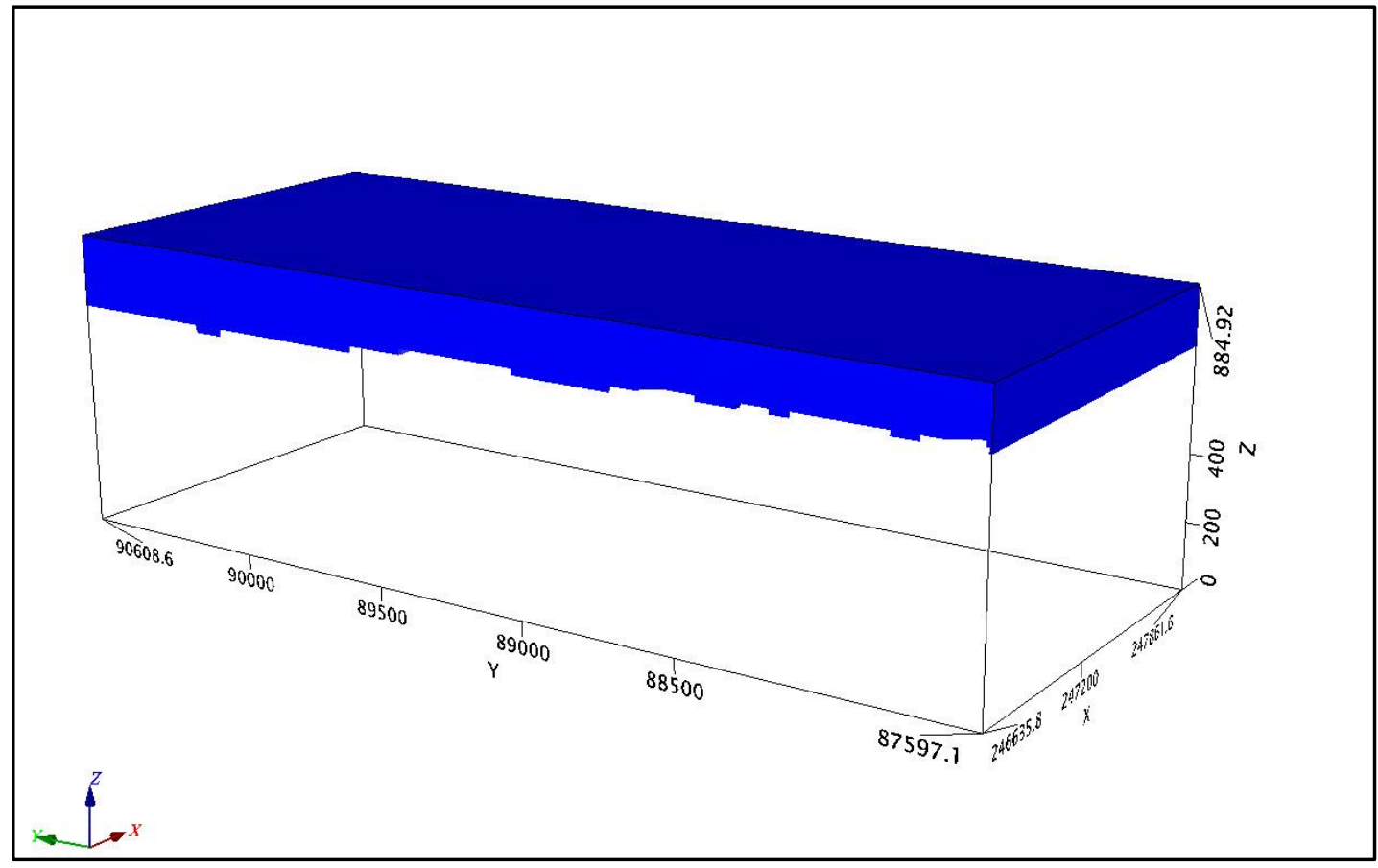

Figure 17:- Magnetic 3D model to a susceptibility $0.1581187 \mathrm{nT}$ (sedimentary cover).

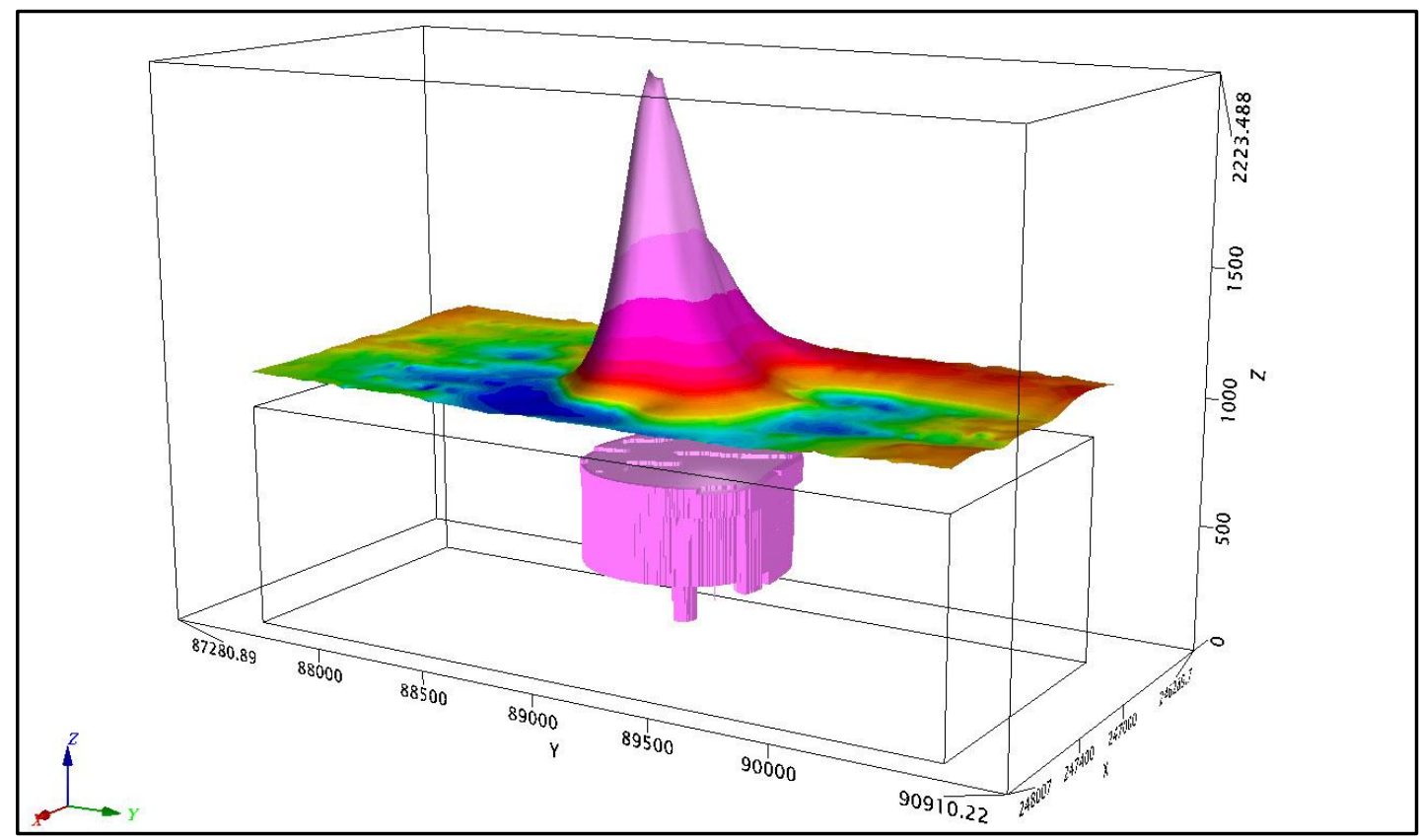

Figure 19: - Magnetic 3D model to a ranging susceptibility from 0.1587 to $0.1633043 \mathrm{nT}$ with its response (Ore body). 


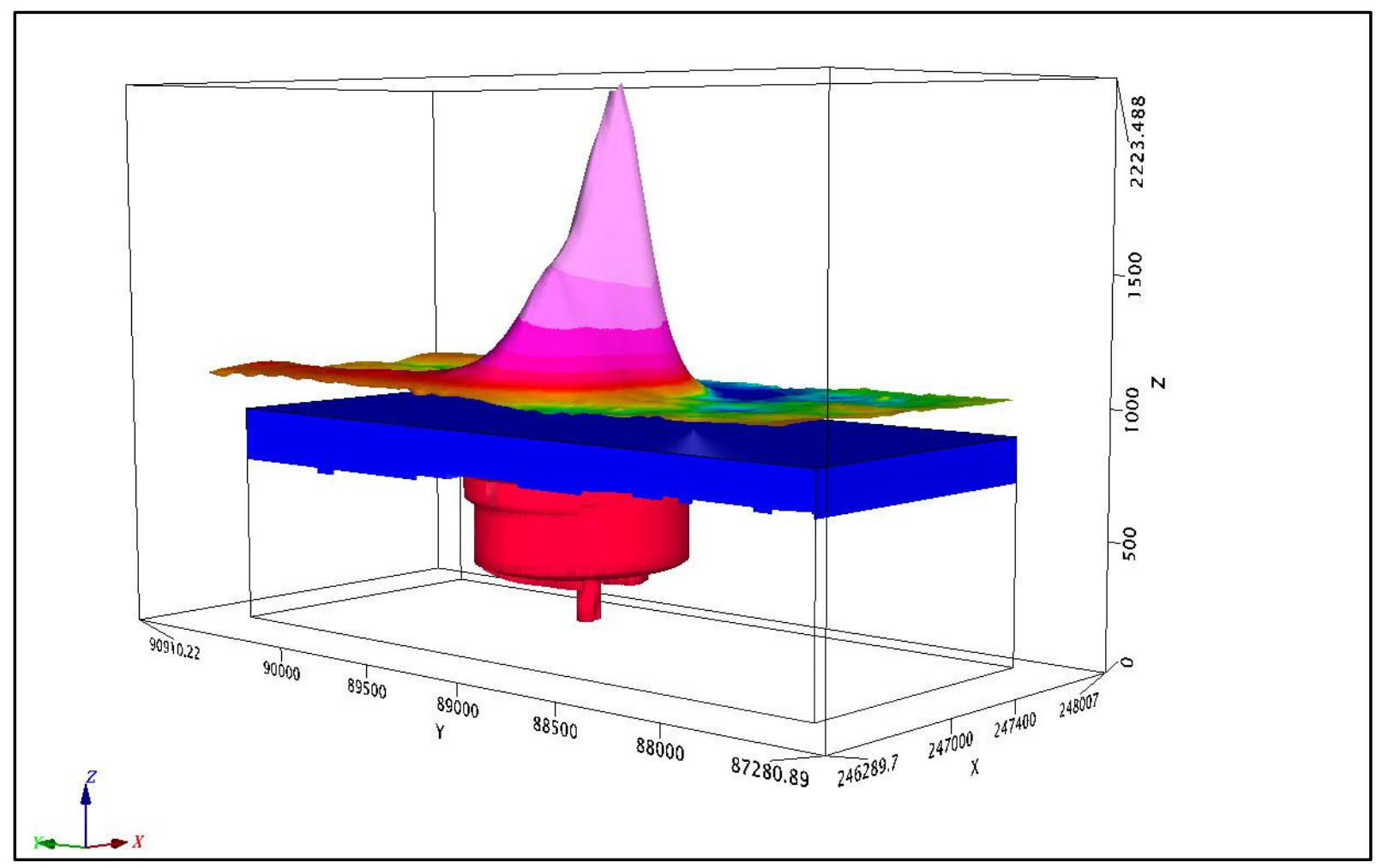

Figure 20: - 3D model of the ore body and the sedimentary cover.

\section{Discussion and Conclusion: -}

The Hajjarmagneticanomaly (Figure 7) is in bipolar form with a lowminimum in the North, and a strong maximum in the South. Its long axis of $1.4 \mathrm{~km}$ takes a direction E-W. It also notes from the magnetic card, that this anomaly is in a quiet magnetic context, which was a favorable factor for identification. In order to define the magnetic materials, we established a discount at the pole of total magnetic field (including anomaly figure) The parameters correspond to an inclination of the regional field $46^{\circ}$ declination is taken to be $7.40^{\circ}$ (El maamar, 1985).

As Reduction, the pole Support, tilt derivative also contributed to the identification of the central body, governed by a magnetic calm context the tilt derivative map contains noise reflected by the regional magnetic effect.

The mineralized body orientation is: (dips: $45^{\circ}$ north) Magnetic methodis a powerful tool in geophysical exploration particularly in mining exploration.

This study was part of the geophysical modeling. She highlighted the contribution of magnetic method in the resource modeling of Hajjar (main body). It is essentially based on the application of the fundamental tools of geophysics (theory, data processing and 2D and 3D modeling).

Furthermore, this study has allowed us to map the distribution of the susceptibility as 3 components $(\mathrm{x}, \mathrm{y}, \mathrm{z})$ in the basement of the region and the décèlement of different parameters that characterize the presence of mineralized bodies in region "essentially the main body" (depth, susceptibility, depth of cover, dip, morphology, volume, ... etc.).

Despite the absence of other methods such as geophysical methods or geostatistics, it turned out that magnetic method is a very powerful tool for the characterization and 2D, 3D modeling of mineral resources. This model developed in our case can be considered as an approach that can be applied generally to different deposits.

This modeling allows the orientation of exploration successor geophysical work (example: by drilling recognition) which will reduce exploration costs and will lead to a rational recognition. 


\section{References: -}

1. Abdelfettah Y. 2009. Inversion conjointe des donnéesmagnétotelluriques et gravimétriques: Application à l'imageriegéophysiquecrustale et mantellique. Thèsedoctorat de l'université de Brest, France, 23-25.

2. Asfirane-Haddadj F. \&Galdeano A. 2000. L'utilisation de la déconvolutiond'Euler et du signal analytique pour la localisation des sources magnétiques, Bulletin de la Société Géologique de France 2000 171, 71-81.

3. Backus, G.E., and Gilbert, J.F., 1967, Numerical applications of a formalism for geophysical in verse problems: Geophy. J. Roy. Astr. Soc., 13, 247-276.

4. Backus, G.E., and Gilbert, J.F., 1968, The resolving power of gross earth data: Geophy. J. Roy. Astr. Soc., 16, 169-205.

5. Backus, G.E., and Gilbert, J.F., 1970, Uniqueness in the inversion of inaccurate gross earth data: Phil. Trans. Roy. Soc. London, 266, 123-192.

6. Blakely, R. J., 1995. Potential theory in gravity \& magnetic applications. Cambridge University Press, pp. 1190.

7. El Goumi N. 2010. Application des méthodesgéophysiques à l'explorationminièredans la région de Marrakech (Maroc). Thèse de Doctorat, Université Cadi Ayyad, Faculté des Sciences et Technique, Marrakech.

8. Farhane R., Souni B., 1999. Traitement et interprétation des donnéesmagnétiques de l'anomalie de Douar HAJJAR, Guemassa (Maroc). Thèse de 3 ème cycle, université Hassan $1{ }^{\mathrm{er}}$ Settat , 23-24.

9. FOUDIL-BEY N. 2012. Développementd'outilsd'interprétation de donnéesgéophysiques. Thèsedoctoratd'université de Lorraine, France, université du Québec en Abitibi-Témiscamingue, Canada, p. 6.

10. Hathouti M. 1990. Etude gravimétrique et magnétique des amassulfurésviséens de la région de Marrakech. Thèsed'université Montpellier, France, p. 51.

11. Hathouti M. 1990. Etude gravimétrique et magnétique des amassulfurésviséens de la région de Marrakech.Thèsed'université Montpellier, France, 55-57.

12. Hathouti M. 1990. Etude gravimétrique et magnétique des amassulfurésviséens de la région de Marrakech.Thèsed'université Montpellier, France, p.103.

13. Hathouti M. 1990. Etude gravimétrique et magnétique des amassulfurésviséens de la région de Marrakech. Thèsed'université Montpellier, France, p. 107.

14. Hibti M. 1993. L'amassulfuré de Hajar :contextegéologique de miseen place et déformationssuperposées. (Haouz de Marrakech, Méséta Sud-Occidentale, Maroc). Thèse de 3 éme cycle, Univ Cadi Ayyad, Marrakech, p. 197.

15. Jackson, D.D., 1972, Interpretation of inaccurate, insufficient and inconsistent data: Geophys. J. Roy. Astr. Soc., 28, 97-109.

16. Keating B.P. 1998. Weighted Euler déconvolution of gravity data. Geophysics, 63, 1595-1603.

17. MAGMAP filtering, How To guide. Copyright 2015 Geosoft Inc. 24 p.

18. Massot J. 2002. Implémentation de méthodes de restauration équilibrée. PhD. Thesis, Institut National Polytechnique de Lorraine (France).

19. Miller, H.G, Singh, V.J., 1994, Potential Field tilt - A new concept for location of potential field sources. Applied Geophysics, v. 32, p. 213-217.

20. Reid A.B. 1995. Euler deconvolution: Past, present and future - A review. 65th SEG meeting, Houston, USA, Expanded Abstracts, 272-273.

21. Thompson D. T. 1982. EULDPH - A new technique for making computer-assisted depth estimates from magnetic data: Geophysics, 47, 31-37.

22. Thompson R., Oldfield F. 1986. Environmental magnetism. Allen and Unwin. 227 p.

23. Thurston, J.B., and Smith, R.S., 1997, Automatic conversion of magnetic data to depth, dip and susceptibility contrast using the SPITM method, Geophysics, v. 62, p. 807-813.

24. Verduzco, B. et al., 2004, New insights into magnetic derivatives for structural mapping, The Leading Edge, v. 23, p. 116-119. 